\title{
Transcriptional activation of caspase -6 and -7 genes by cisplatin-induced p53 and its functional significance in cisplatin nephrotoxicity
}

\author{
C Yang ${ }^{1}$, V Kaushal ${ }^{1}$, RS Haun ${ }^{2}$, R Seth ${ }^{1}$, SV Shah ${ }^{1}$ and GP Kaushal ${ }^{\star, 1,3}$
}

This study examined the role of cisplatin-induced p53 activation in regulation of caspases and cellular injury during cisplatin nephrotoxicity. The executioner caspase- 6 and -7 but not caspase- 3 were identified as transcriptional targets of p53 in cisplatin injury as revealed by chromatin immunoprecipitation, a reporter gene and electrophoretic mobility shift assays, and real-time PCR following overexpression and inhibition of p53. DNA binding by p53 involved the first introns of the human and mouse caspase-7 gene and the mouse caspase- 6 gene. Studies in human kidney, breast, ovary, colon, and prostate tumor cell lines also validated these findings. Treatment of p53 $(-I-)$ cells with cisplatin did not induce caspase- 6 and -7 expression and subsequent activation. In caspase-3 $(-I-)$ cells, inhibition of caspase- 6 and -7 activations markedly prevented cisplatin-induced cell death. In an in vivo model of cisplatin nephrotoxicity inhibition of p53 activation by a p53 inhibitor suppressed transactivation of the caspase- 6 and -7 genes and prevented renal failure. p53 $(-I-)$ mice were resistant to cisplatin nephrotoxicity as assessed by renal function and histology. These studies provide first evidence for p53-dependent transcriptional control of the caspase-6 and -7 genes and its functional significance in cisplatin injury to renal cells and functional implication of cisplatin-induced p53 induction in vitro and in vivo in cisplatin nephrotoxicity.

Cell Death and Differentiation (2008) 15, 530-544; doi:10.1038/sj.cdd.4402287; published online 7 December 2007

\begin{abstract}
One of the major side effects of cisplatin chemotherapy, used for several solid tumors, is nephrotoxicity or toxic acute kidney injury (AKI). ${ }^{1,2}$ Cisplatin preferentially accumulates in the kidney and induces damage to the kidney primarily in the S3 segment of proximal tubules with some damage to distal nephrons. ${ }^{1,2}$ Although several targets of cisplatin in cells have been characterized, the primary biological target is generally considered to be DNA. ${ }^{3}$ Cisplatin causes DNA damage due to its ability to form a platinum-DNA complex. ${ }^{3,4}$ The underlying cellular response by which cisplatin-induced DNA damage triggers cell death in renal tubular epithelial cells (RTECs) is not fully understood. One of the major cellular responses to DNA damage inflicted by cisplatin and related cellular stresses in a variety of cells involves upregulation of p53 protein, which is usually undetectable in normal cells. ${ }^{5,6}$ Upon activation, p53 binds to specific DNA sequences that promote transcription of target genes, including genes associated with apoptosis and cell cycle arrest, ${ }^{6-9}$ in a tissue- and cell-specific manner. ${ }^{10,11}$

Upon receiving a proapoptotic stimulus, most if not all of the signaling pathways of cell death converge into the activation of executioner caspase- $3,-6$, and -7 . The initiator caspase-2, $-8,-9$, and -10 , having long $\mathrm{N}$-terminal prodomains, activate the downstream executioner caspases with short $\mathrm{N}$-terminal prodomains by proteolytic processing. Thus regulation of the
\end{abstract}

expression of executioner caspases is crucial prior to the execution of cell death. Several studies including ours have previously demonstrated activation of executioner caspases (caspase-3/7 and -6) in both in vitro ${ }^{12,13}$ and in vivo ${ }^{14,15}$ models of cisplatin-induced AKI. Similarly, induction of p53 transcription factor was demonstrated in RTECs in both in vitro $^{16-18}$ and in vivo ${ }^{19}$ studies of cisplatin AKI. Inhibiting the activation of $p 53$ protein by pifithrin- $\alpha$, a pharmacological inhibitor of p53, blocked caspase activation. ${ }^{16-18}$ One of the mechanisms whereby p53 can control caspase activation is by direct transcriptional regulation of their expression. However, transcriptional control of caspases and the functional significance of this regulation are not known in renal injury. The expression of the caspase- $1,{ }^{20}-6,{ }^{21}$ and $-10^{22}$ genes has been shown previously to be transcriptionally controlled by $\mathrm{p} 53$ in vitro. Despite these studies, no comprehensive study has been performed on transcriptional regulation of caspases in any in vitro or in vivo models of cellular injury.

In the present study, we have explored p53-dependent transcriptional expression of the caspase genes and its implication in cisplatin nephrotoxicity. We have identified and characterized caspases that are transcriptionally responsive to $p 53$ in both in vitro cell cultures of RTECs and in an in vivo experimental model of cisplatin nephrotoxicity. In

\footnotetext{
1John L McClellan Memorial Veterans Hospital, Central Arkansas Veterans Healthcare System and Department of Internal Medicine, University of Arkansas for Medical Sciences, Little Rock, AR 72205, USA; ${ }^{2}$ Department of Pathology, University of Arkansas for Medical Sciences, Little Rock, AR 72205, USA and ${ }^{3}$ Department of Biochemistry, University of Arkansas for Medical Sciences, Little Rock, AR 72205, USA

${ }^{*}$ Corresponding author: GP Kaushal, Department of Medicine, University of Arkansas for Medical Sciences, Slot 501, 4301 W. Markham Street, Little Rock, AR 72205, USA. Tel: 501/257 5834; Fax: 501/257 5827; E-mail: kaushalgurp@uams.edu

Keywords: p53; caspase-6; caspase-7; transcription; cisplatin; apoptosis

Abbreviations: AKI, acute kidney injury; ChIP, chromatin immunoprecipitation; PAS, periodic acid-Schiff stain; Pidd, p53-induced protein with a death domain; RTECs, renal tubular epithelial cells; siRNA, small interfering RNA; Z-DEVD-fmk, benzyloxycarbonyl-Asp-Glu-Val-Asp-amino-4-fluoromethylketone

Received 29.3.07; revised 13.9.07; accepted 05.11.07; Edited by V De Laurenzi; published online 07.12.07
} 
addition, we have explored the functional significance of p53 and p53-induced caspase expression and their subsequent activation in cisplatin injury in vitro in RTECs and in vivo in cisplatin nephrotoxicity.

\section{Results}

p53-dependent upregulation of mRNA and protein levels of caspase- 6 and -7 but not of caspase-3, -8 , and -9 . The dependency of p53 in mRNA expression of caspases was explored by upregulating p53 or inhibiting p53. Treatment of RTECs with cisplatin or transfection with Ad-p53 vector exhibited a striking induction of p53 expression (Figure 1a). Control Ad-LacZ transfection did not induce p53 expression. The p53 small interfering RNA (siRNA) efficiently and specifically silenced cisplatin-induced p53 expression (Figure 1b). Semiquantitative RT-PCR analysis revealed a marked increase in p53-dependent expression of the caspase- 6 and -7 genes but not of the caspase-3, -8, and -9 genes (Figure 1c). Overexpression of p53 by Ad-p53 or by cisplatin treatment upregulated caspase- 6 and -7 mRNA levels while pifithrin- $\alpha$ or p53 siRNA downregulated these transcripts (Figure 1c). The mRNA levels of caspase-3, -8 , and -9 were not affected by overexpression of p53 or by treatment with pifithrin- $\alpha$ or p53 siRNA. Cisplatin-induced mRNA expression of caspase- 6 and -7 in p53 $(+/+)$ cells but not in p53 (-/-) cells (Figure 1d) further confirmed that p53 deficiency affects caspase- 6 and -7 expression. To quantify the p53-dependent cisplatin-induced changes in mRNA expression of caspases, real-time PCR was performed. Cisplatin treatment induced caspase- 6 and -7 mRNA expression by 4- and 12-fold, respectively, while no significant changes in the mRNA expression of caspase-3, -8 , and -9 were observed (data for caspase- 8 and -9 are not shown) (Figure 2a). Pifithrin- $\alpha$ or p53 siRNA markedly downregulated cisplatin-induced caspase- 6 and -7 transcripts while overexpression of p53 by Ad-53 significantly increased their expression (Figure 2a). The protein expression of caspase- 6 and -7 was also increased by p53 overexpression in a time-dependent manner (Figure $2 b$ ), suggesting that a p53-dependent increase in mRNA of caspase- 6 and -7 was also reflected in the increased protein expression. Similar results were obtained with cisplatin treatment (data not shown). Taken together, these studies indicate that transcription of the caspase- 6 and -7 genes but not of the caspase- $3,-8$, and -9 genes is regulated by $\mathrm{p} 53$.

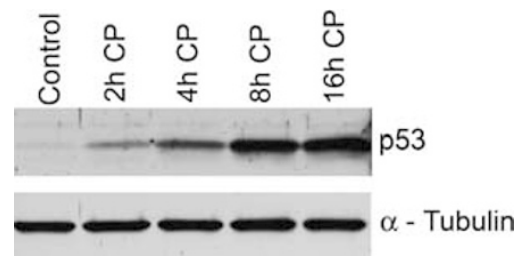

C

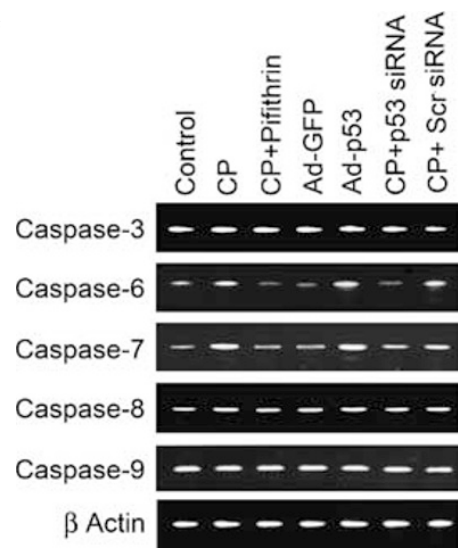

b

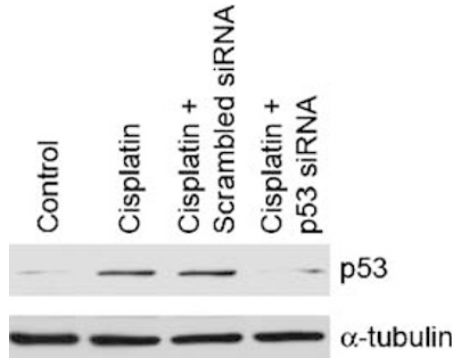

d

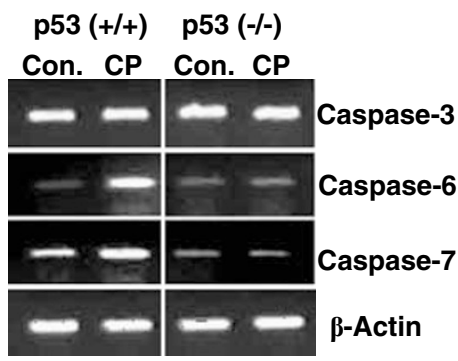

Figure 1 p53-dependent cisplatin (CP)-induced mRNA and protein expression of caspases. (a) p53 induction in CP-induced injury to renal tubular epithelial cells (RTECs). TKPTS cells were treated with $25 \mu \mathrm{M}$ CP for various times as indicated and p53 expression was determined by western blot using p53 antibody. (b) Effect of p53 small interfering RNA (siRNA) on CP-induced p53. TKPTS cells were transfected with p53 siRNA or scrambled siRNA and treated with and without CP (25 $\mu$ M) as described in the Materials and Methods section. Cell lysates were prepared and analyzed for p53 by western blot using anti-p53 antibody. Blot for $\alpha$-tubulin confirmed equal loading of the samples. (c) Semiquantitative RT-PCR of caspase transcripts following overexpression or inhibition of p53 or CP treatment. TKPTS cells grown in 60 -mm culture dishes were infected with Ad-53 or Ad-lacZ or treated with $\mathrm{CP}(25 \mu \mathrm{M})$ in the presence or absence of pifithrin- $\alpha(25 \mu \mathrm{M})$ or p53 siRNA. For siRNA transfection, $0.1 \mathrm{nM}$ p53 siRNA and $10 \mu \mathrm{l}$ lipofectamine were mixed in $1 \mathrm{ml}$ Opti-MEM prior to transfection. For p53 overexpression, Ad-p53 was used for infection at a multiplicity of infection of 50, for $24 \mathrm{~h}$. RT-PCR was performed as described in the Materials and Methods section. (d) Semiquantitative RT-PCR analysis of caspase transcripts in p53 (+ $/+)$ and p53 (-I-) cells. Wild-type p53 RTECs and p53-deficient RTECs were prepared from kidneys of p53 $(+/+)$ and p53 $(-/-)$ mice. RT-PCR was performed as described in the Materials and Methods sections 

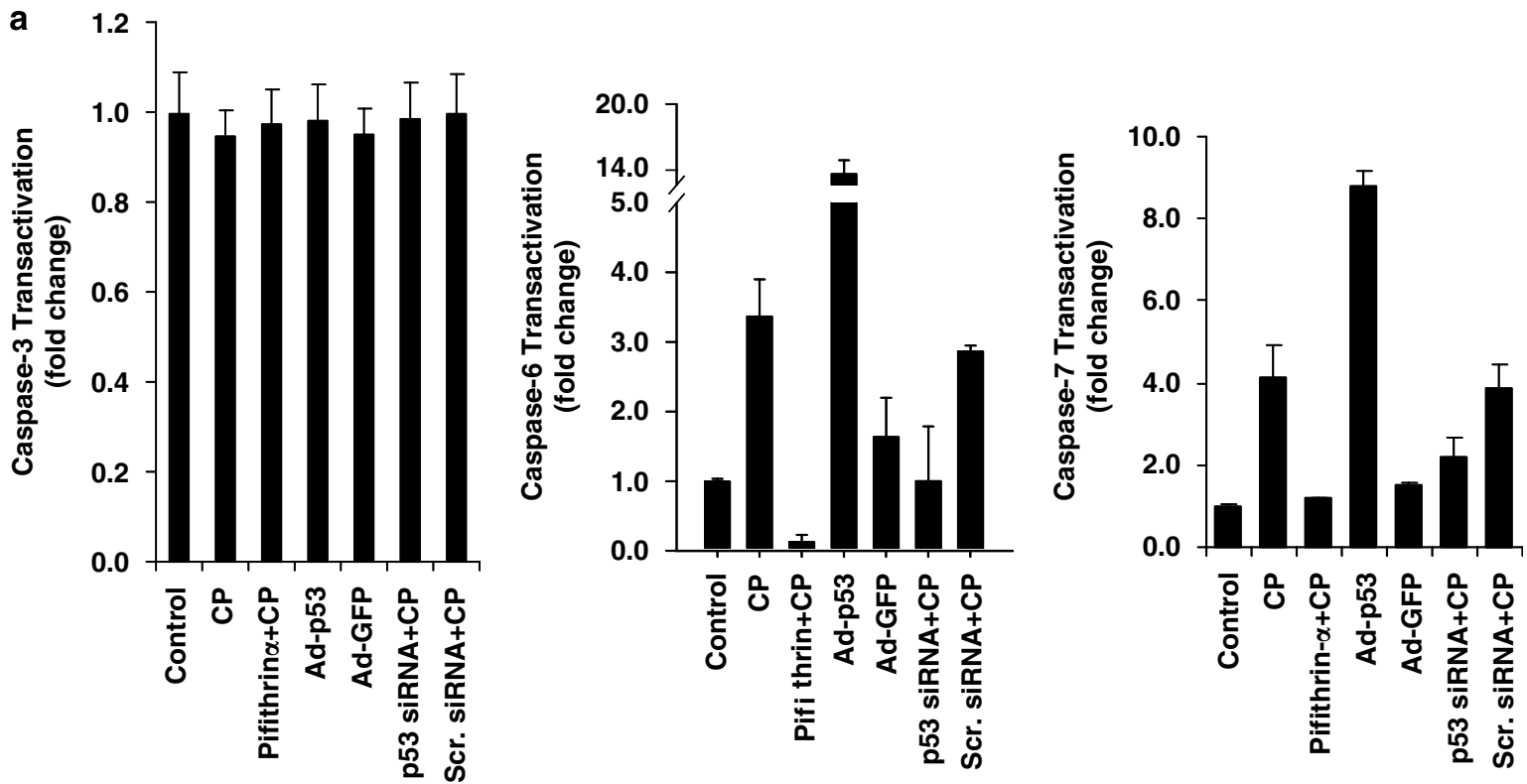

b

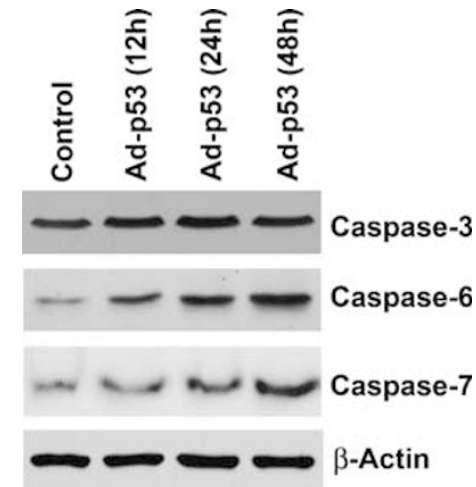

Figure 2 Quantitative real-time RT-PCR analysis of p53-responsive cisplatin (CP)-induced transcription expression of caspases in renal tubular epithelial cells (RTECs) in vitro. (a) Quantitative real-time RT-PCR. TKPTS cells were treated with CP $(25 \mu \mathrm{M})$ in the presence or absence of p53 inhibitor pifithrin- $\alpha(25 \mu \mathrm{M})$ or p53 small interfering RNA (siRNA), or infected with Ad-p53 or Ad-lacZ. Levels of caspase-3, -6 , and -7 transcripts were determined using quantitative RT-PCR. The results are mean \pm S.E. $(n=3$ independent experiments). (b) Time course of p53-dependent upregulation of protein expression of caspase-6 and -7. TKPTS cells were infected with Ad-p53 (at a multiplicity of infection of 50 ) or Ad-lacZ for various times as indicated. Cell lysates were immunoblotted with antibodies to procaspase-3, -6 , and -7

Identification of p53-binding sites in genomic sequences of caspases. We searched for potential p53binding sites in the genomic sequences of caspases using the web-based TESS (Transcription Element Search System) and Genomatix software. The consensus p53 response element consists of two copies of $5^{\prime}-\mathrm{PuPuPu}$ $\mathrm{C}(\mathrm{A} / \mathrm{T})(\mathrm{T} / \mathrm{A}) \mathrm{GPyPyPy}-3^{\prime}$ separated by $0-21 \mathrm{bp} .{ }^{7,23}$ As shown in Figure $3 a$, caspase- 6 and -7 genes contained p53 consensus binding sites whereas no p53-binding sites were found in caspase- $-3,-2,-8$, and -9 genes. Human caspase- 6 gene has been identified previously as a transcriptional target of p53 (involves binding of p53 to the third intron). ${ }^{21}$ The p53-binding sites in mouse and human caspase-7 have not been previously identified. We observed p53 consensus binding sites within the first intron of the human and mouse caspase- 7 gene, and the first intron of the mouse caspase- 6 gene (Figure $3 a$ ). The search did not reveal the presence of p53 DNA-binding sites in the promoter region. In fact, the first intron of mouse caspase-7 gene revealed the presence of p53 DNA-binding sites at positions $+4088,+7199,+8918$, and +9091 . When these sites were tested by a chromatin immunoprecipitation (ChIP) assay, only the site at +7199 showed a clear positive immunoprecipitation with p53 antibody upon cisplatin treatment or p53 overexpression (Figure 3b). The site at +9091 showed a positive but relatively weak ChIP assay product upon p53 overexpression and showed no response upon cisplatin treatment. Sites at position +4088 and +8918 did not show positive responses. When the primers (at site -2298 to -113 ) for promoter region were used, the ChIP assay did not amplify a product. For the caspase- 6 gene, the precipitated DNA amplified primers specific to p53-binding sites of the first intron of caspase- 6 gene. p53-induced protein with a death domain (Pidd) with a high-affinity p53-binding site served as a positive control (Figure $3 b$ ). The p53 binding to the mouse caspase- 7 genes through the site at +7199 was determined 
a

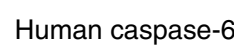

(15.7 kb)

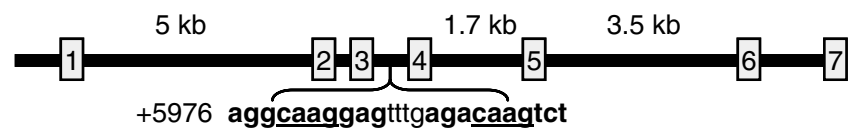

Mouse caspase- 6

(13.3 kb)

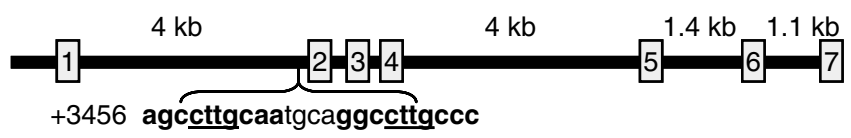

Human caspase-7

(52.5 kb)

+3953 aggcatgcaccaccatgccc

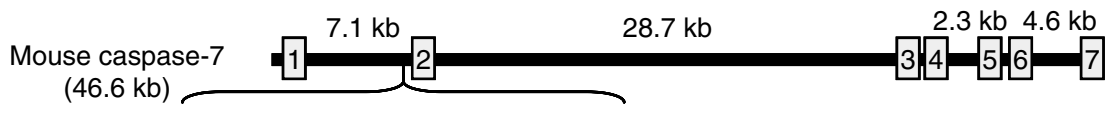

+7199 agacttgtcccacacgtggacacacacacaatcacaaggct

b chr

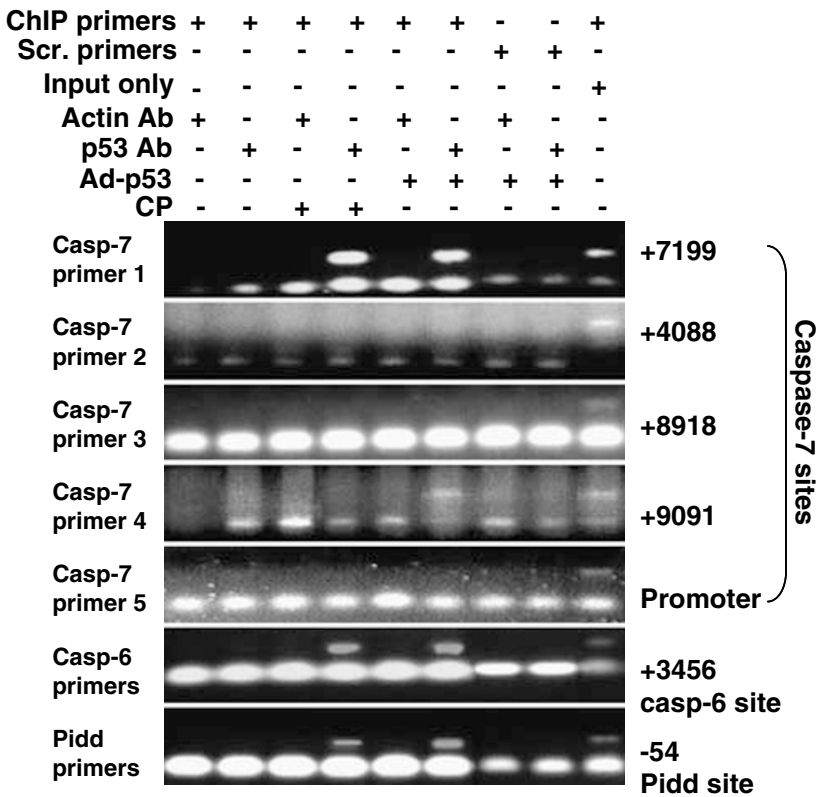

c

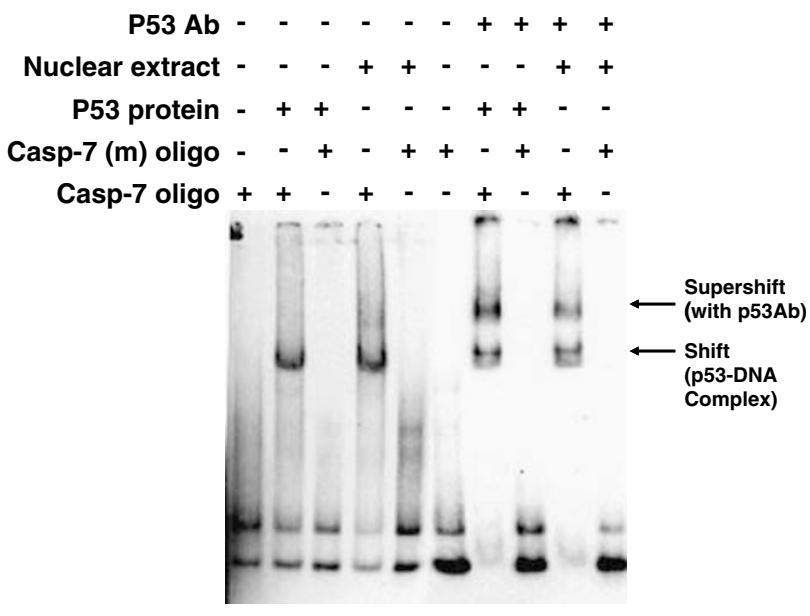

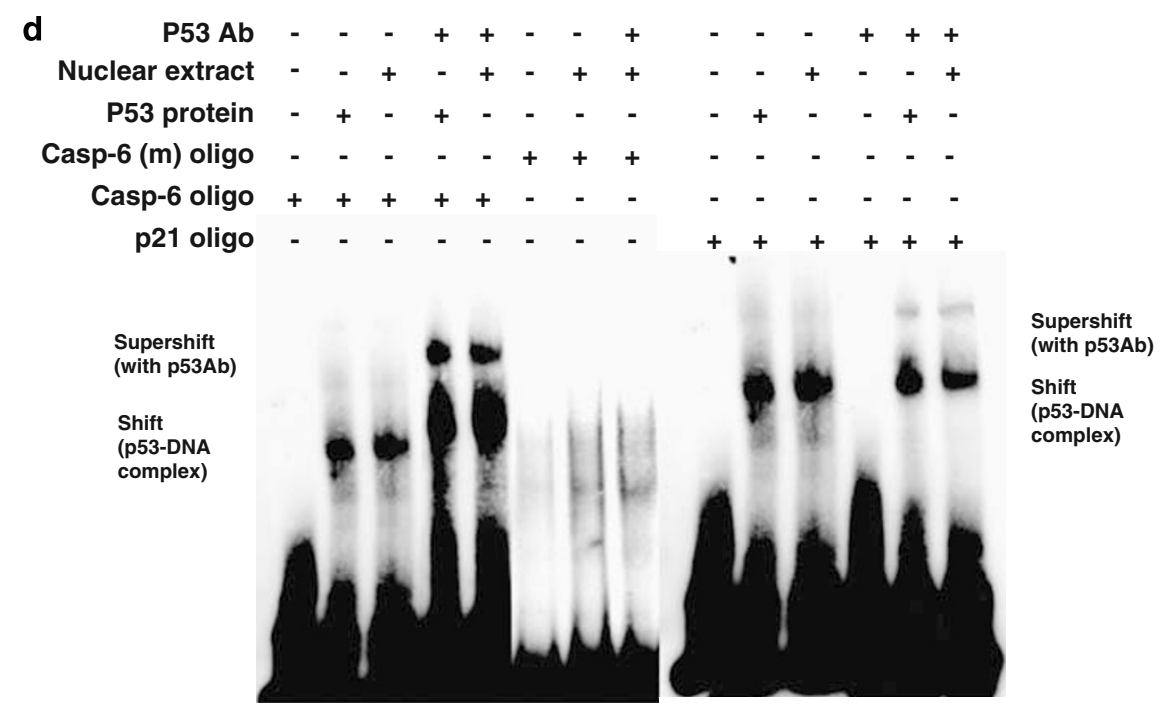

Figure 3 Continued 

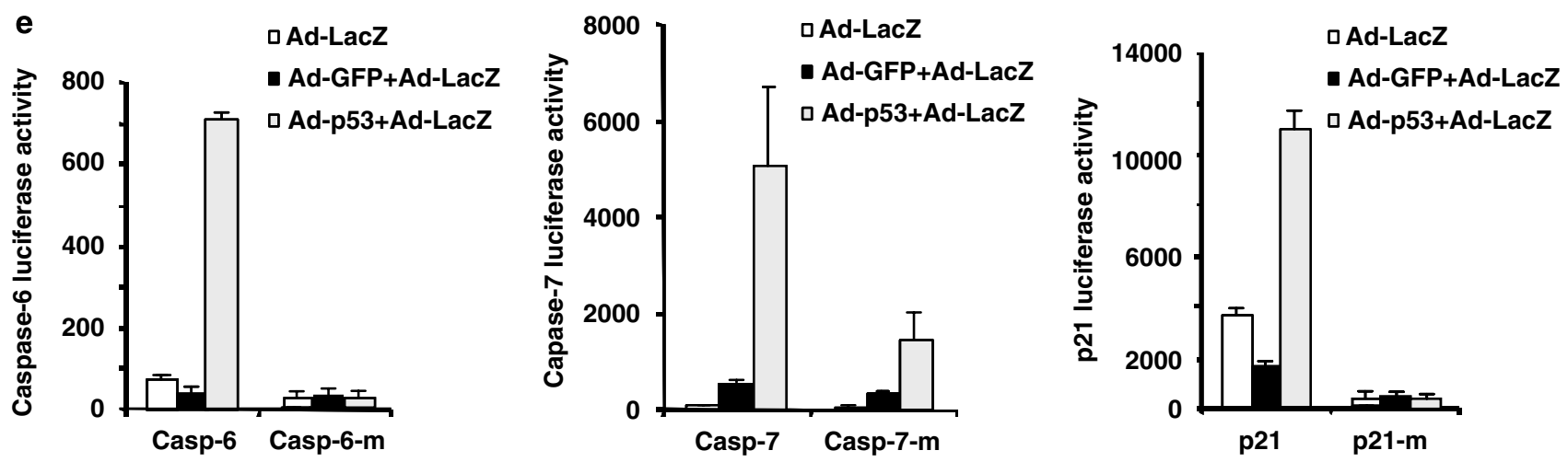

f

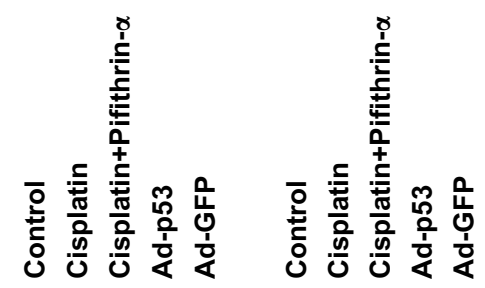

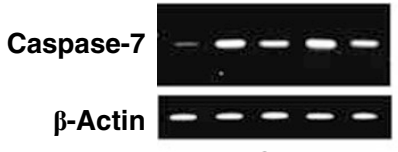

MCF-7

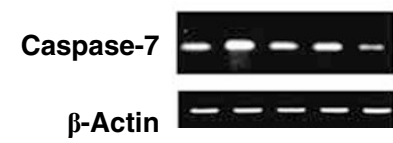

HEK-293

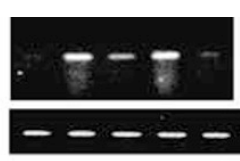

PA-I

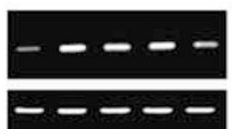

LNCap

Figure 3 Identification of p53-binding sites in genomic sequences of caspase- 6 and -7. (a) Scheme of genomic structures of the mouse and human caspase-6 and -7 genes. The bars represent the exons separated by introns varying in size. The position of the sequences containing p53-binding consensus site and nucleotides in bold (underlined) corresponding to the conserved consensuses sequence CWWG (W =A or T) are shown. (b) Chromatin immunoprecipitation (ChIP) assay. TKPTS cells, either untreated or treated with cisplatin (CP), as well as the cells infected with Ad-p53 were subjected to ChIP with antibodies directed against either p53 or $\beta$-actin (negative control). The precipitated DNA was subjected to PCR amplification using a set of primers specific to the potential p53-binding sites as shown in the figure. Scrambled primer sets were employed as well for the specificity control. The p53-induced protein with a death domain (pidd) gene served as a positive control. The input lane contained about $1 \%$ of the total input chromatin before immunoprecipitation. Primers 1-4 correspond to sites 1-4 in the first intron of the caspase-7 gene, respectively. (c) Electrophoretic mobility shift assay (EMSA) for the mouse caspase-7 gene. EMSA was performed by binding of biotinylated oligonucleotides with either purified p53 protein or nuclear extracts. p53 antibodies were used for obtaining supershift due to p53Ab-p53-DNA complex. Binding reactions as shown were performed using the LightShift Chemiluminescent EMSA Kit. (d) EMSA for the mouse caspase-6 gene. Binding reactions of biotinylated oligonucleotides for caspase-6 and p21 (used as a positive control) with recombinant p53 protein as shown were performed using the LightShift Chemiluminescent EMSA Kit. Supershift was observed when p53 antibodies were used in reaction mixtures containing binding oligos, nuclear extract, or p53 protein. (e) Activation of the caspase- 6 and -7 genes by p53 using luciferase assays. Plasmid constructs containing DNA fragments corresponding to $\mathrm{p53}$-binding sites in caspase- 6 and -7 , or the same DNA fragments containing mutated p53 sites were cloned into luciferase reporter constructs containing an E1b minimal promoter. TKPTS cells were co-transfected with indicated reporter constructs, Ad-LacZ vector as an internal control, and Ad-p53 or Ad-green fluorescent protein (GFP). Luciferase activities were determined using the Promega Luciferase System Kit with a luminometer. Plasmid construct with p53-binding site in the p21 gene was used as a positive control. The results are mean values of three independent experiments \pm S.E. (f) Induction of human caspase-7 mRNA by p53. Four human cell lines as shown were treated with $\mathrm{CP}(25 \mu \mathrm{M})$ in the presence or absence of the p53 inhibitor pifithrin- $\alpha(25 \mu \mathrm{M})$ or infected with Ad-53 or Ad-GFP. Total RNA was extracted using an RNeasy kit and semiquantitative RT-PCR was performed

by an electrophoretic mobility shift assay (EMSA) using synthetic oligonucleotides corresponding to the consensus binding site. A clear shift in the oligonucleotide band following the incubation of the consensus site specific oligonucleotides in the first intron of the mouse caspase-7 gene with nuclear extracts (prepared from cisplatin-treated RTECs) or purified recombinant $\mathrm{p} 53$ protein (Figure $3 \mathrm{c}$ ) indicated formation of a p53-DNA complex. A strong supershift observed on addition of p53 antibody confirmed the presence of p53 in the protein-
DNA complex (Figure 3c). Similar results for p53 binding to the human caspase-7 gene were obtained (data not shown). For the binding of the mouse caspase- 6 gene to $p 53$, the oligonucleotides corresponding to the consensus sites in the first intron of the mouse caspase- 6 gene were used (Figure 3d). p21 having high affinity p53-binding site was used as a positive control. For the human caspase- 6 gene, formation of p53-DNA complex has been shown previously by EMSA. ${ }^{21}$ In addition, the luciferase-reporter constructs for 


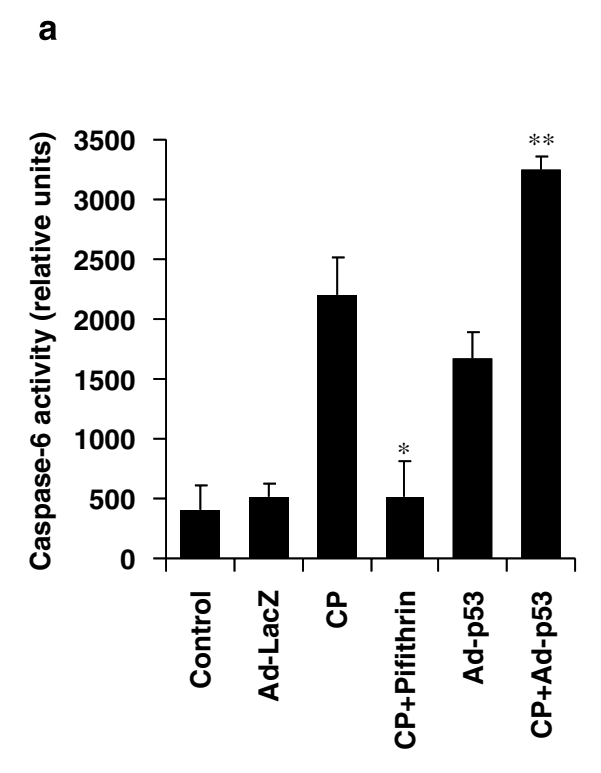

b
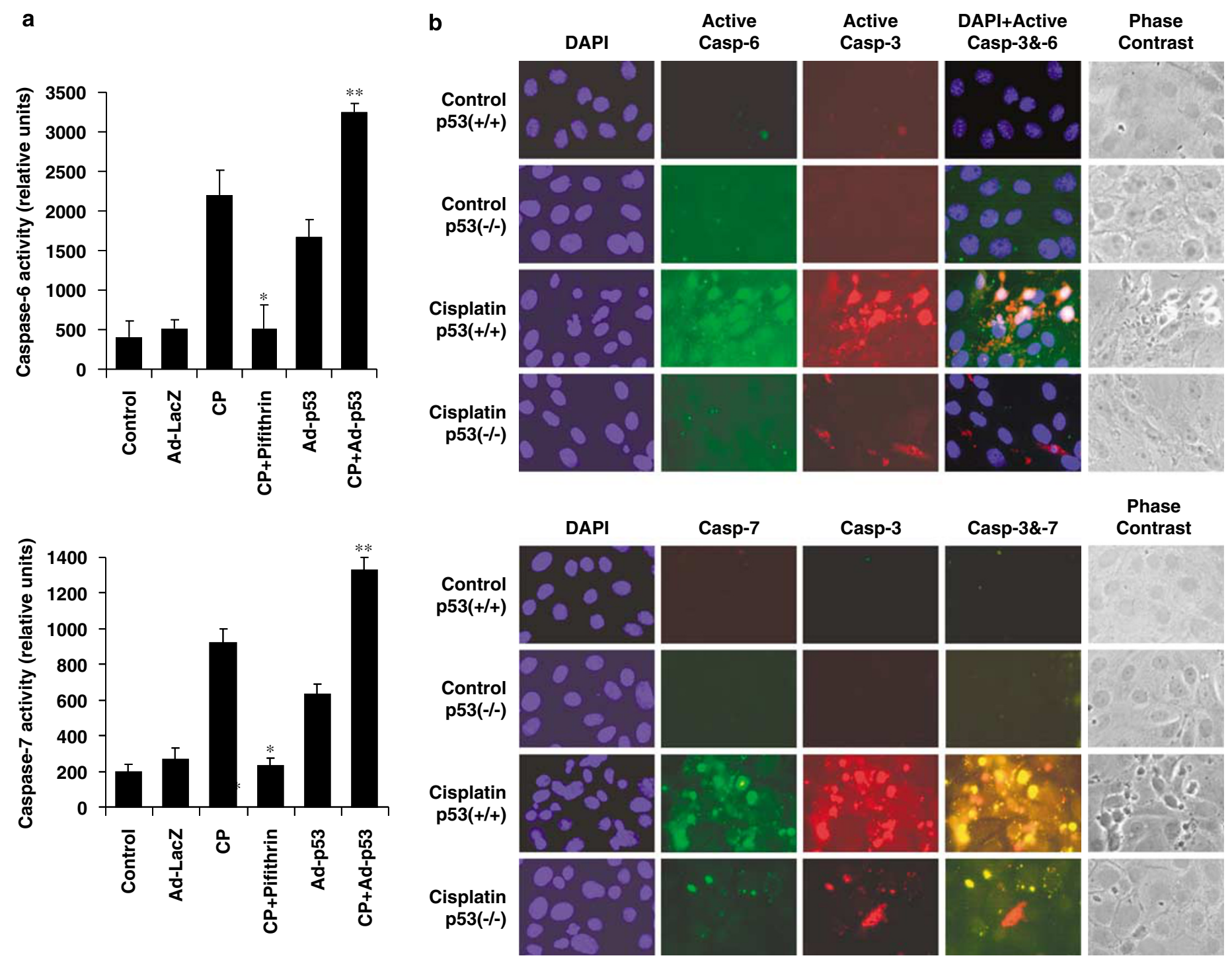

Figure 4 Continued 


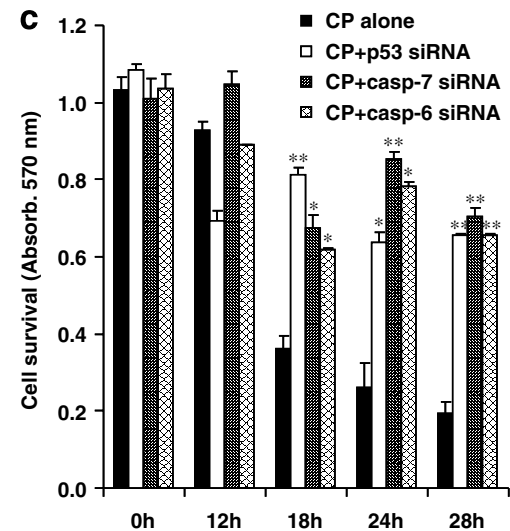

Caspase-3 $(t+)$ cells treated with $\mathrm{CP}^{2}$

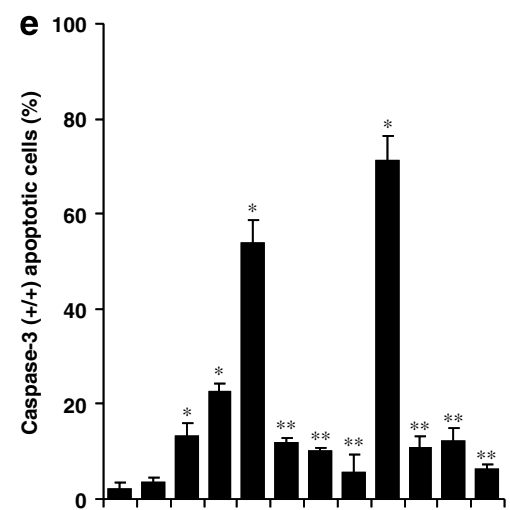

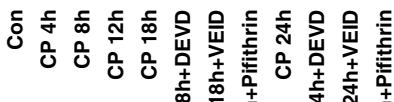

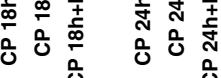
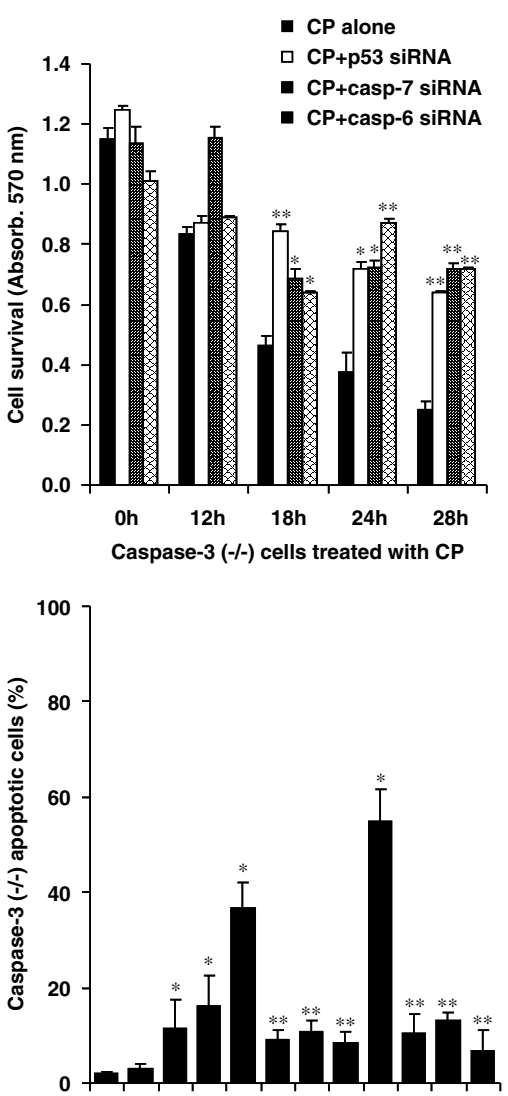

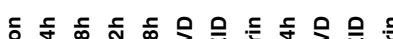

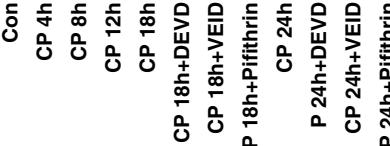

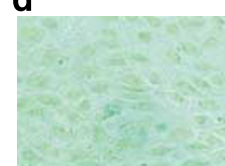

Caspase-3 $3(+/+)$ renal tubular cells

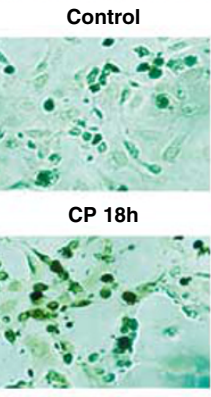

CP 24h

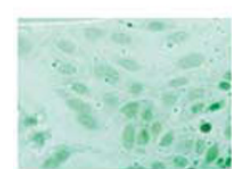

Control

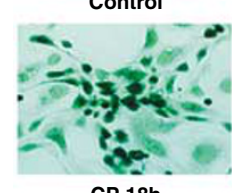

CP $18 \mathrm{~h}$

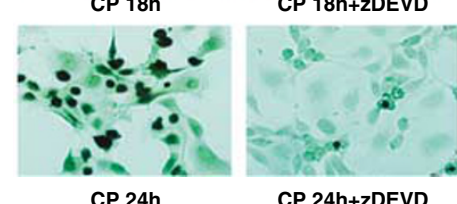

CP 24h

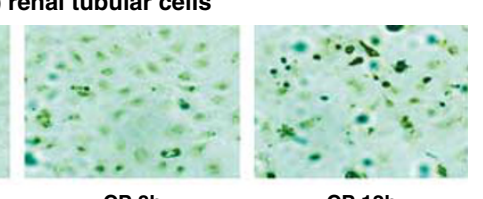

$\mathrm{CP} 8 \mathrm{~h}$

CP 12h

Figure 4 p53-dependent activation of caspase-6 and -7 and effect of inhibition of caspase- 6 and -7 or p53 on cisplatin (CP)-induced cell death. (a) Effect of downregulation and upregulation of p53 on activation of caspase-6 and -7. Primary renal tubular epithelial cell (RTEC) cultures prepared from kidneys of caspase-3 $(-/-)$ and caspase- $3(+/+)$ mice were treated with CP or CP + pifithrin- $\alpha$ or infected with Ad-p53 or Ad-LacZ for control, as indicated. Caspase- 6 and -7 activities in cell lysates $(50 \mu$ g of protein) were determined using DEVD-AMC and VEID-AMC fluorogenic substrates, respectively. Caspase activities are shown as relative units. The results are mean \pm S.E. $\left(n=4,{ }^{*} P<0.01\right.$ compared to CP, ${ }^{\star \star} P<0.02$ compared to Ad-p53). (b) p53 (-l-) RTECs are resistant to CP-induced activation of caspase-3, -6 , and -7 . Primary cultures of RTECs were prepared from kidneys of p53 $+I+$ and p53- - - mice. Cells were untreated or treated with $50 \mu \mathrm{M} \mathrm{CP}$ for $16 \mathrm{~h}$ and were double immunostained with antibodies to active caspase-3 (red) and active caspase-6 (green) or active caspase-7 (green) and active caspase-3 (red), respectively, followed by staining with $4^{\prime}, 6^{\prime}$-diamidino-2-phenylindole (DAPI) (blue). CP-treated p53 $+1+$ cells show activation of executioner caspases whereas p53 (- $/-$ ) cells were quite resistant to activation. The appearance of pink-yellow color in p53 $(+1+)$ cells indicates colocalization of active caspase-3 and -6 or active caspase-3 and -7. (c) Effect of inhibition of caspase-6 and -7 or p53 on cell survival upon CP treatment. Caspase-3 $(+/+)$ and caspase-3 (-I-) RTECs were untreated or treated with CP at 12, 18, 24, and $28 \mathrm{~h}$ following transfection with caspase-6, caspase-7, or p53 small interfering RNAs (siRNAs) as described in the Materials and Methods section. MTT (3-(4,5-dimethylthiazol-2-yl)-2,5-diphenyltetrazolium bromide) assays were performed to determine the relative amounts of viable cells. Results are mean $\pm \mathrm{S}$.E. $\left(n=4\right.$, ${ }^{*} P<0.04$ compared with $\mathrm{CP}$-treated cells, ${ }^{\star *} P<0.01$ compared with CP-treated cells). (d) Inhibition of caspase- 6 and -7 or pifithrin- $\alpha$ block CP-induced apoptosis. Caspase- $3(-/-)$ and caspase- $3(+/+)$ RTECs were untreated or treated with CP or CP + pifithrin- $\alpha$ or caspase inhibitors as indicated. The appearance of apoptotic nuclei in a representative field was revealed by the TUNEL method as described in the Materials and Methods section. (e) Quantitative analysis of apoptosis on inhibition of caspase- 6 and -7 or p53 revealed in (d) by the TUNEL method. The apoptotic cells were counted in five fields, and compared by two-tailed unpaired $t$-tests between the two groups. $\left(n=5\right.$, ${ }^{*} P<0.05$ compared with $\mathrm{CP}$-treated cells, ${ }^{* *} P<0.01$ compared with $\mathrm{CP}$-treated cells) 
caspase- 6 and -7 containing the intronic regions that bind p53 were generated. These constructs were responsive to the wild-type $\mathrm{p} 53$ binding but not to the constructs containing a mutated p53-binding site (Figure 3e). A p21 luciferasereporter construct was used as a positive control (Figure $3 e$ ). Similar results for human caspase- 6 and -7 were obtained (data not shown). These data indicate that the p53-binding elements of the caspase- 6 and -7 genes are capable of recruiting p53 to activate transcription of caspase- 6 and -7 genes.

Induction of caspase-7 expression by p53 in human cancer cell lines. The dependency of p53 in cisplatininduced expression of endogenous caspase-7 mRNA was also explored by inhibiting as well as upregulating p53 expression in human cell lines having an endogenous wildtype p53 gene. The human embryonic kidney cell line HEK293 and three human cancer cell lines, MCF-7, PA-1, and $\mathrm{LNCaP}$, were treated with cisplatin or transfected with a Adp53 vector or treated with p53 inhibitor pifithrin- $\alpha$, and total RNA was isolated to examine caspase-7 expression. All of these cell lines are known to induce wild-type p53 in response to genotoxic stress. These showed an efficient p53 gene transfer with $90-100 \%$ cells stained for green fluorescent protein (GFP) when Ad-GFP was used as a control. The induction of p53 expression and inhibition by pifithrin- $\alpha$ was monitored by western blot (data not shown). Semiquantitative RT-PCR revealed that caspase-7 expression was significantly increased with either Ad-p53 or by cisplatin treatment and the expression was suppressed by pifithrin- $\alpha$ (Figure 3f).

p53 overexpression and/or cisplatin treatment results in enhanced activation of caspase -6 and -7 and a p53 inhibitor or use of p53 $(-I-)$ cells prevent caspase activation. We examined the possibility that p53-dependent increase in the protein levels of procaspase- 6 and -7 will result in higher activation of these executioner caspases. Our previous study showed significant activation of caspase-3/7 and -6 by cisplatin treatment. ${ }^{12}$ Caspase- 3 and -7 utilize the same substrate DEVD-AMC and therefore the activities determined by cleavage of DEVD-AMC are in fact contributed by both of these caspases. To specifically examine cisplatin-induced caspase-7 activation, we used primary cultures of caspase-3 (-/-) RTECs prepared from the kidneys of caspase-3 (-/-) mice. Caspase- 6 and -7 activities were significantly increased with cisplatin treatment or overexpression of p53 (Figure 4a). A p53 inhibitor pifithrin- $\alpha$ markedly prevented cisplatin-induced caspase- 6 and -7 activation. To examine further the specific role of p53 in activation of executioner caspases, we prepared RTECs from p53 (-/-) and p53 $(+/+)$ mice. Immunofluorescent studies using specific antibodies to the active forms of executioner caspases revealed that compared to p53 $(+/+)$ cells, p53 $(-/-)$ cells were effective in blocking activation of caspase-3, -6 , and -7 (Figure 4b). These studies show that p53-deficient RTECs were quite resistant to activation of executioner caspases.
Inhibition of p53 or p53-dependent caspase-6 and -7 activation significantly prevents and delays cisplatininduced cell death. To investigate the potential functional significance of p53-dependent caspase- 6 and -7 activation by cisplatin we used an RNA interference (RNAi) approach for the specific inhibition of caspase- 6 and -7. As cisplatininduced caspase- 3 activation may also contribute to cell death we used caspase-3 (-/-) RTECs for specific inhibition of caspase- 6 or -7 . Inhibition of caspase- 6 or -7 by their respective siRNA resulted in cell survival (as revealed by MTT (3-(4,5-dimethylthiazol-2-yl)-2,5-diphenyltetrazolium bromide) assay) and delayed cisplatin-induced cell death (Figure 4c). However, p53 inhibition was more effective in preventing cell death as compared to the inhibitors that blocked caspase- 6 and -7 . Inhibition of caspase- 6 and -7 or p53 was effective in preventing cisplatin-induced apoptosis (Figure 4d and e).

p53 regulates caspase expression and activation in vivo in cisplatin nephrotoxicity. The p53 protein, barely detectable in normal kidneys, gradually accumulated mostly in the nuclei with some staining in the cytosol from $4 \mathrm{~h}$ through 3-day progression of cisplatin nephrotoxicity (Figure 5a). Pifithrin- $\alpha$ markedly inhibited cisplatin-induced p53 protein expression (Figure $5 \mathrm{a}$ and b). Semiquantitative RT-PCR revealed that expression of the caspase- 6 and -7 genes were responsive to $p 53$. Pifithrin- $\alpha$ markedly reduced mRNA expression of caspase -6 and -7 genes at 1,2 , and 3 days following cisplatin administration (data not shown). Pifithrin- $\alpha$ had no effect on the expression of caspase-3, -8, and -9 transcripts (data not shown). The expression of caspase transcripts were quantified and confirmed by realtime PCR (Figure 5c). Thus, among the cisplatin-induced caspase-3, $-6,-7,-8$, and -9 genes, caspase- 6 and -7 genes were responsive to p53 inhibition. Cisplatin treatment increased caspase- 6 and -7 protein expression during the progression of cisplatin nephrotoxicity (Figure $5 d$ ). Cisplatininduced activation of executioner caspases was significantly blocked by pifithrin- $\alpha$ (Figure $5 e$ ). These studies indicate that the p53-dependent transcriptional regulation of caspase- 6 and -7 genes in vivo is similar to that observed in cell cultures.

p53 inhibitor pifithrin- $\alpha$ or p53 (-I-) mice ameliorates cisplatin-induced renal failure. Renal function as determined by blood urea nitrogen (BUN) and creatinine values demonstrated that pifithrin- $\alpha$ significantly ameliorated cisplatin-induced AKI (Figure 6a). The improvement in renal function was also reflected in kidney histology (Figure 6b). Cisplatin treatment induced severe tubular injury characterized by extensive loss of tubular epithelial cells, loss of brush border membranes, tubular dilation, intratubular debris, sloughing of tubular epithelial cells, and cast formation. Animals treated with cisplatin and pifithrin- $\alpha$ resulted in significant recovery from the severe tubular injury (Figure 6b). Semiquantitative evaluation of kidney sections showed tubular necrosis score of $0.06 \pm 0.02$ in kidneys from mice treated with $5 \%$ dimethylsulfoxide (DMSO) in saline alone, $0.07 \pm 0.03$ in kidneys from mice treated with pifithrin- $\alpha$ alone, $3.4 \pm 0.5$ in kidneys from mice treated with cisplatin for 


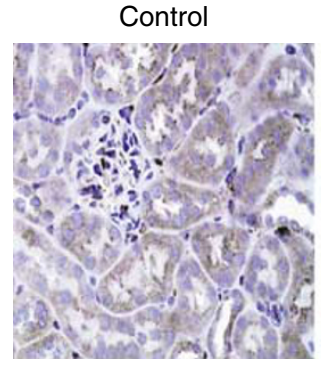

4h CP

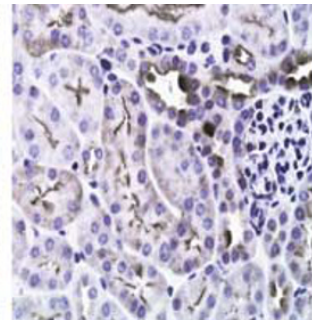

$16 \mathrm{~h} \mathrm{CP}$

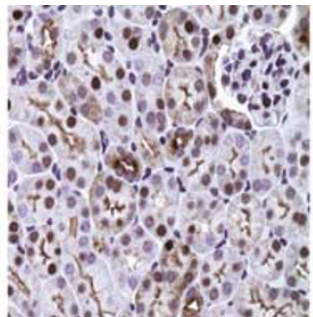

3D CP

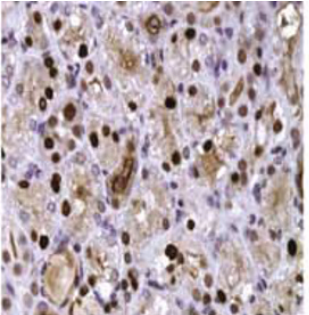

$3 \mathrm{D} C P+$ Pifithrin- $\alpha$

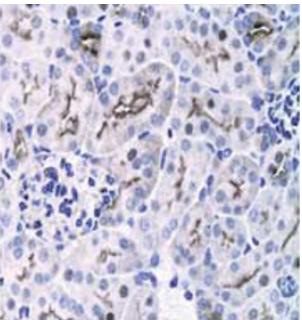

b
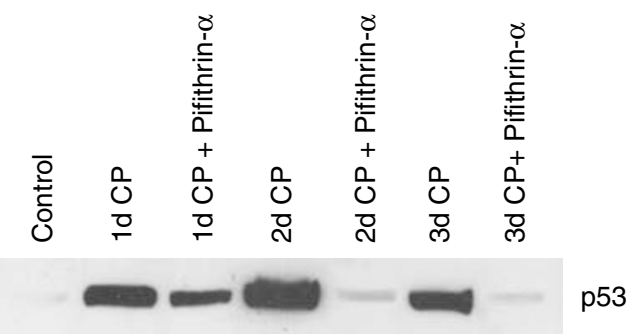

C
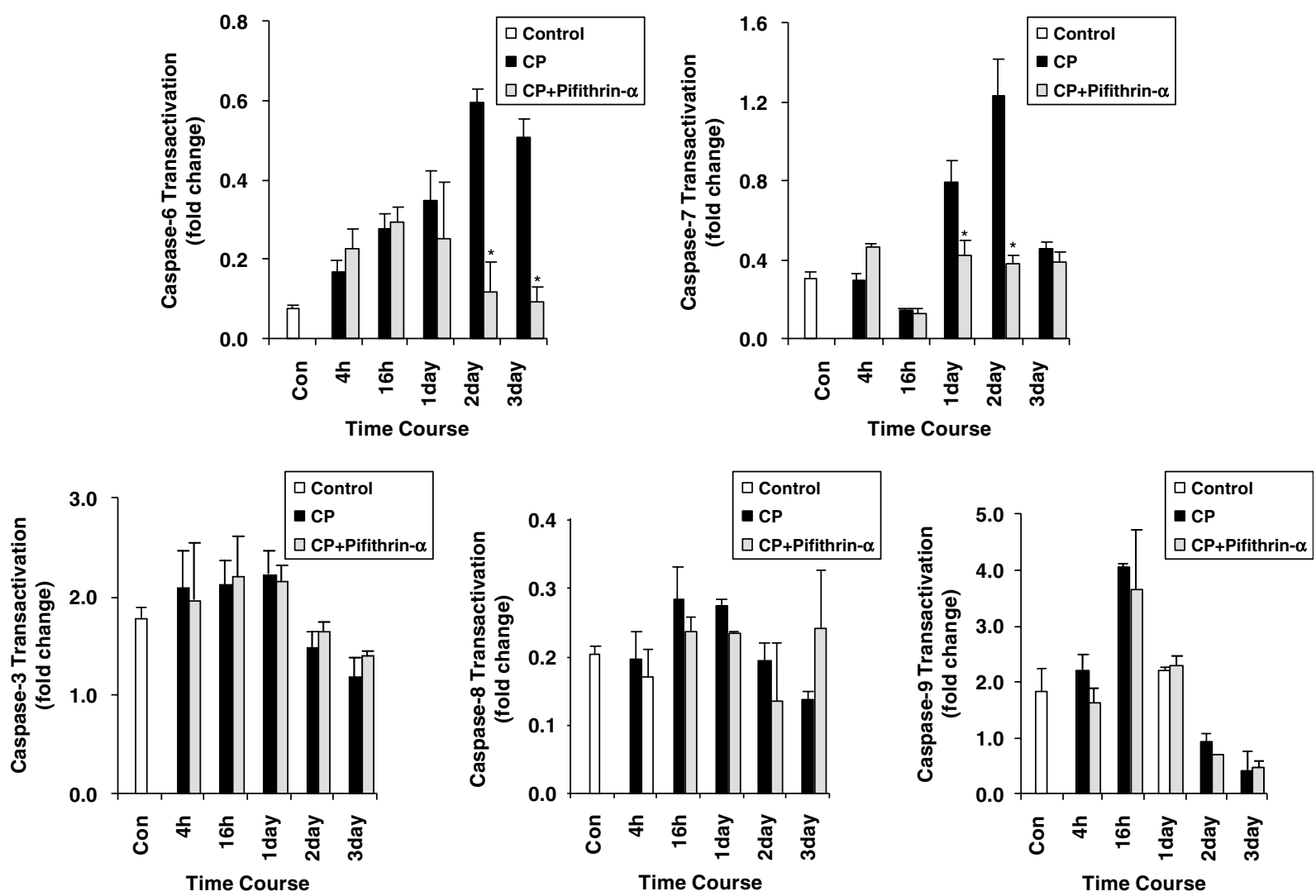

Figure 5 p53-dependent mRNA expression of caspases in vivo. (a) Induction of p53 expression in cisplatin (CP)-induced acute kidney injury in vivo. An in vivo model of $\mathrm{CP}$ nephrotoxicity was developed as described in the Materials and Methods section. Kidney sections were prepared and used to analyze p53 distribution by immunohistochemistry using polyclonal antibody to p53. (b) Western blot of p53 protein expression in CP-induced AKI and inhibition by pifithrin- $\alpha$. Extracts from kidney following CP-induced AKI were analyzed for p53 by western blot analysis. (c) Quantitative real-time RT-PCR analysis of caspase transcripts in kidneys in vivo in acute kidney injury and effect of p53 inhibitor pifithrin- $\alpha$. The experimental model of acute kidney injury was developed as described in the Materials and Methods section and used in Figure 6. Total RNA from kidneys was isolated using an RNeasy kit and levels of caspase- 6 and -7 transcripts as well as levels of caspase-3, -8 , and -9 were determined using quantitative RT-PCR. The results are mean \pm S.E. ( $n=4$ independent experiments, $P<0.004$ versus day $1 \mathrm{CP}+$ pifithrin- $\alpha$ ). (d) Caspase- 6 and -7 protein expression during the progression of $\mathrm{CP}$ nephrotoxicity. Mice were injected intraperitoneally with either $\mathrm{CP}(20 \mathrm{mg} / \mathrm{kg}$ body weight (b.w.)) or CP with pifithrin- $\alpha$ for 1-, 2-, and 3-day period. At the indicated times, kidneys were harvested and kidney tissues were used to determine the protein expression of caspase-6 and -7 by western blot analysis. (e) Activation of executioner caspases during the progression of CP nephrotoxicity. Mice were injected intraperitoneally with either $\mathrm{CP}(20 \mathrm{mg} / \mathrm{kg} \mathrm{b} . \mathrm{w}$.) or CP with pifithrin- $\alpha$ for $16-\mathrm{h}, 1$-day, 2-day, and 3-day period. At the indicated times, kidneys were harvested and kidney cortices were used to determine the activities of various caspases using DEVD-AMC and VEID-AMC fluorogenic substrates for caspase-3/7 and -6 , respectively 
d

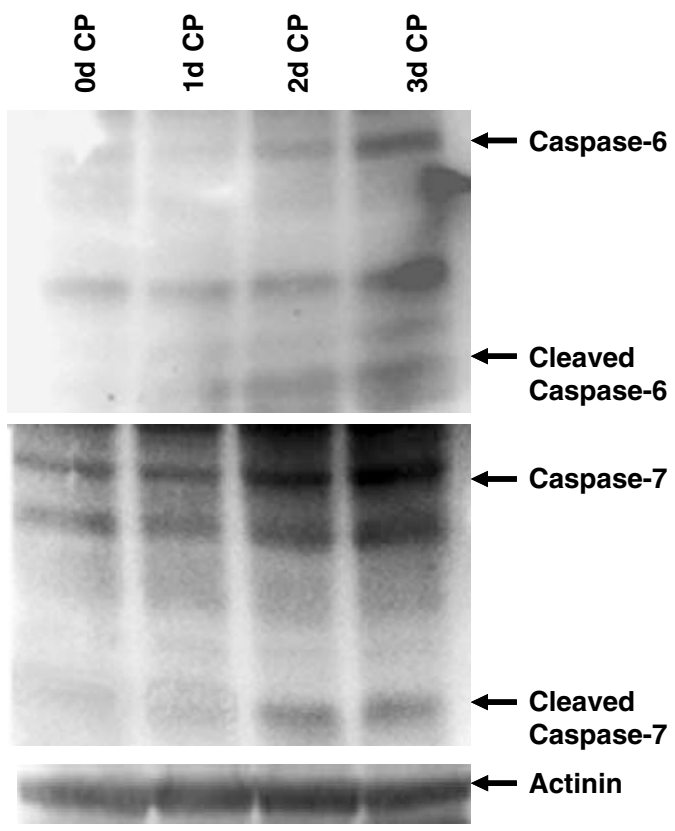

e
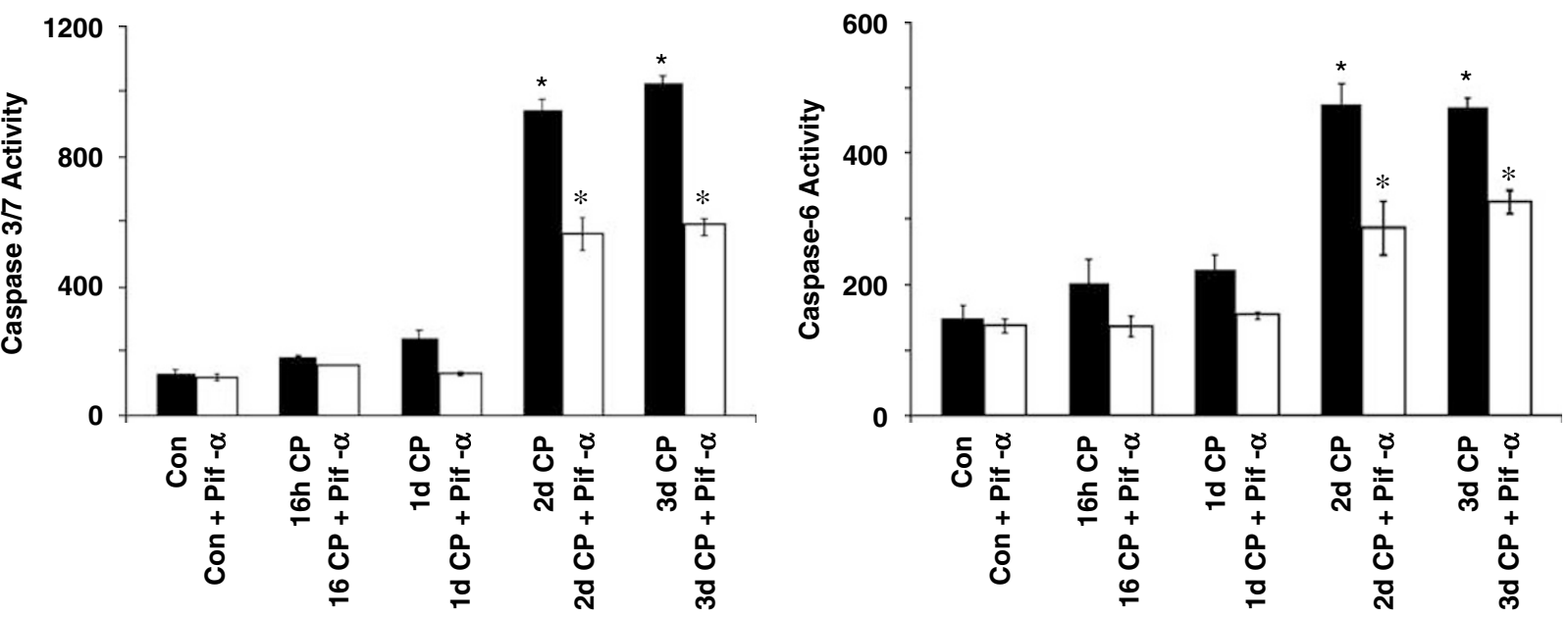

Figure 5 Continued

3 days, and $0.3 \pm 0.08$ in kidneys from mice treated with cisplatin and pifithrin- $\alpha$ for 3 days. The protective effect of p53 inhibition on acute renal failure was also determined using p53 (-/-) mice. As shown in Figure 6c and d p53 $(-/-)$ mice provided significant protection from cisplatininduced $\mathrm{AKI}$ as shown by a reduction in BUN and serum creatinine values (Figure $6 \mathrm{c}$ ) and improvement in kidney morphology and tubular integrity (Figure 6d). These studies thus demonstrate that p53 activation in response to cisplatin plays an important role in the progression of cisplatin nephrotoxicity.

\section{Discussion}

One of the well-characterized functions of activation of p53 is its transcriptional activity, which influences the transcription of several downstream target genes. ${ }^{24}$ In the present study, we have identified the caspases that are transcriptionally controlled by p53 in response to cisplatin in RTECs in culture and in an experimental model of cisplatin nephrotoxicity. We demonstrate that cisplatin-induced $p 53$ transcriptionally regulates expression of the caspase- 6 and -7 genes but not the caspase-3, -8 , and -9 genes. In response to cisplatin or p53 overexpression, caspase- 6 and -7 mRNAs and proteins as well as their activation were considerably increased. Under these conditions mRNA and protein levels of caspase-3, -8, and -9 were not increased. These observations are the first report of p53-dependent transcriptional control of caspases in vivo and in vitro in response to cisplatin.

A genomic sequence search of these caspases indicates the presence of p53 DNA-binding response elements located in the regulatory regions of these genes. The sequence and location of the p53-binding site in the mouse caspase- 6 and the mouse caspase-7 genes is based on the consensus site motif. Previous studies have reported the p53-binding element in the human caspase- $1,,^{20}-6,{ }^{21}$ and $-10^{22}$ genes. 
a
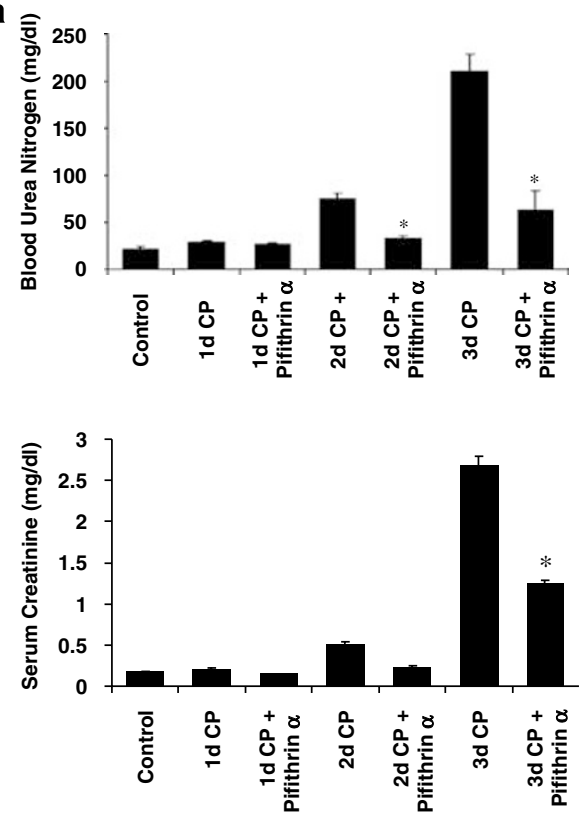

C
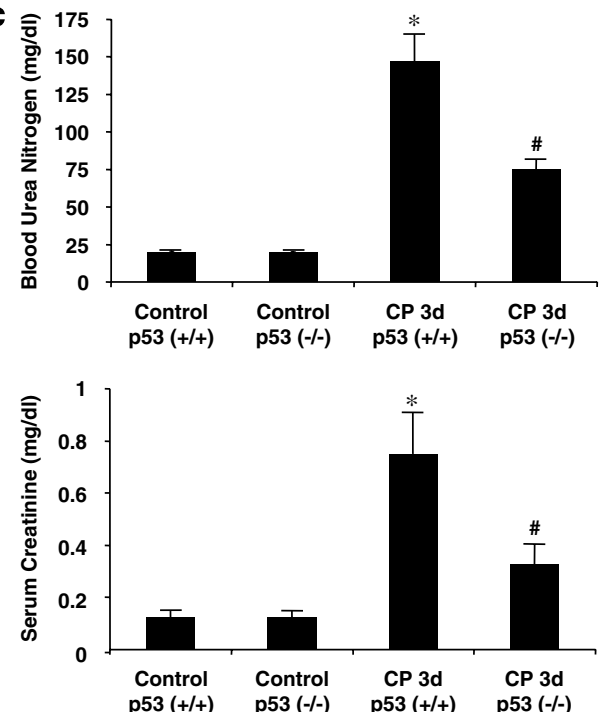

b

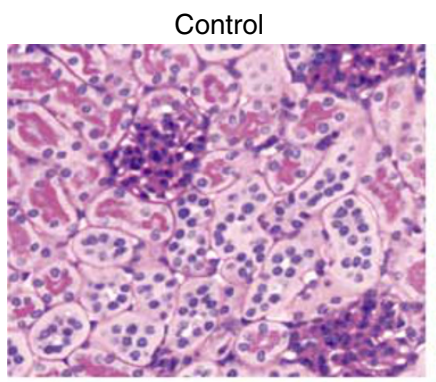

3d CP

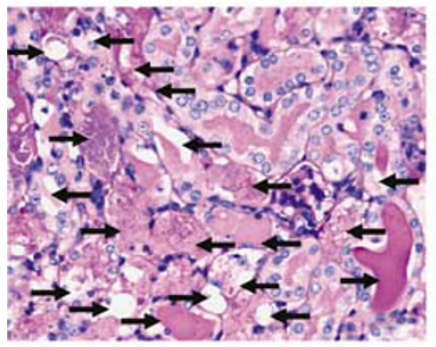

d

Control p53 (+/+)

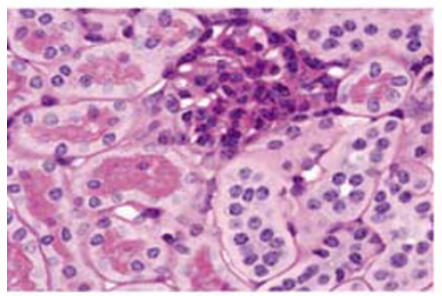

3d Cisplatin p53 (+/+)

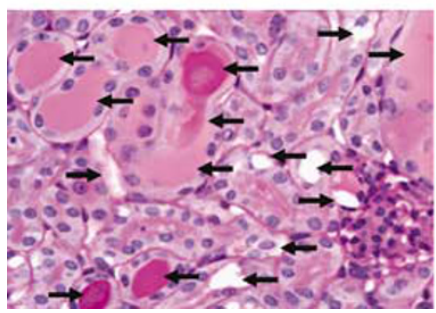

Pifithrin- $\alpha$

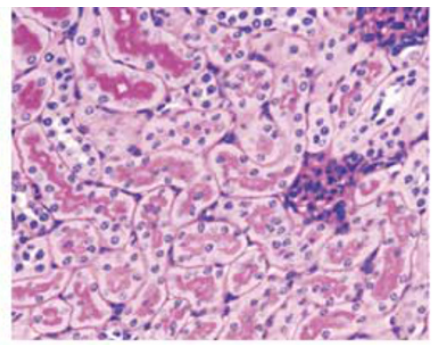

3d CP + Pifithrin $\alpha$

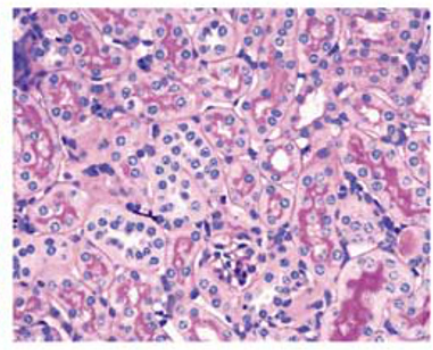

Figure 6 Effect of the p53 inhibitor pifithrin- $\alpha$ on renal function and histology in cisplatin (CP)-induced acute kidney injury. (a) Effect of p53 inhibitor pifithrin- $\alpha$ on blood urea nitrogen (BUN) and serum creatinine. Mice were injected intraperitoneally with either CP (20 mg/kg b.w.) or CP with pifithrin- $\alpha$ for 1-, 2-, and 3-day period. At the indicated times, (upper panel) BUN $\left(n=6,{ }^{*} P<0.005\right)$ and (lower panel) serum creatinine $\left(n=5,{ }^{\star} P<0.01\right)$ levels were determined using a diagnostic kit from International Bioanalytical Industries, FL, USA. (b) Effect of pifithrin- $\alpha$ on kidney morphology in CP-induced AKI. Kidneys from mice were removed 3 days after intraperitoneal administration of $5 \%$ dimethyl sulfoxide (DMSO) in saline (control), $2 \mathrm{mg} / \mathrm{kg}$ b.w. pifithrin- $\alpha$ in $5 \%$ DMSO in saline (control + pifithrin- $\alpha$ ), $20 \mathrm{mg} / \mathrm{kg}$ b.w. CP (3-day CP), and CP and pifithrin- $\alpha$ (3-day CP + pifithrin- $\alpha$ ). Kidneys were fixed in 10\% formalin and kidney sections were stained with periodic acid-Schiff stain (PAS). (Control) Kidney sections from mice treated with $5 \%$ DMSO in saline showed normal morphology with intact renal tubular epithelial cells (RTECs) and well-preserved brush border membranes. (Pifithrin- $\alpha$ ) Mice treated with pifithrin- $\alpha$ alone showed normal RTECs morphology. (1-day CP) Kidneys from mice treated with CP alone showed very little tubular damage or loss of RTECs. (3-day CP) Kidneys from mice treated with CP for 3 days show excessive loss of RTECs, tubular dilation, intratubular debris, and cast formation (shown by arrowheads). (3-day $\mathrm{CP}+$ pifithrin- $\alpha$ ) Kidneys from mice treated with $\mathrm{CP}$ and pifithrin- $\alpha$ for 3 days showed relatively normal tubular morphology with no loss of RTECs and preservation of brush border membranes. (c) p53 (-I-) mice resist CP-induced rise in BUN and creatinine and ameliorate renal dysfunction. p53 $(+/+)$ mice and p53 $(-/-)$ mice were injected intraperitoneally with either saline in $5 \%$ DMSO or CP $\left(20 \mathrm{mg} / \mathrm{kg} \mathrm{b.w}\right.$.) for 1-, 2-, and 3-day period. At the indicated times, (upper panel) BUN $\left(n=6,{ }^{\#} P<0.05\right)$ and (lower panel) serum creatinine $\left(n=5,{ }^{\#} P<0.02\right)$ levels were determined using a diagnostic kit from International Bioanalytical Industries, FL, USA. (d) Effect on kidney morphology in p53 $(-I-)$ mice during CP-induced AKI. Kidneys from p53 $(+/+)$ and p53 $(-I-)$ mice were removed 3 days after intraperitoneal administration of $5 \%$ DMSO in saline (control) or $20 \mathrm{mg} / \mathrm{kg} \mathrm{b.w.} \mathrm{CP} \mathrm{(3-day} \mathrm{CP).} \mathrm{Kidneys} \mathrm{were} \mathrm{fixed} \mathrm{in} \mathrm{10 \%} \mathrm{formalin} \mathrm{and} \mathrm{kidney} \mathrm{sections} \mathrm{were} \mathrm{stained} \mathrm{with} \mathrm{periodic} \mathrm{acid-Schiff} \mathrm{stain} \mathrm{(PAS).} \mathrm{Compared} \mathrm{to} \mathrm{the} \mathrm{kidney}$ morphology of p53 $(+/+)$ mice, the kidneys from p53 $(-/-)$ mice treated with CP for 3 days showed relatively normal tubular morphology with no loss of RTECs and preservation of brush border membranes. The tubular damage in 3-day CP treatment is shown by arrowheads 
Caspase-7 was shown to be induced in response to p53 in a variety of cell lines. A recent study showed that caspase-7 is a p53 responsive gene but the p53-binding site was not identified. ${ }^{25}$ In these studies, it was suggested that the caspase-7 gene may bind to p53 through the promoter region within $-1000 \mathrm{bp}$. However, no consensus binding site for p53 was found in this region in the human or mouse caspase-7 gene. The primers in the promoter region when used from the position -2298 to -113 in ChIP assay did not amplify a product. Our studies showed that DNA binding by p53 involved the first intron of the human and mouse caspase-7 gene. We have found four p53 DNA-binding consensus sites in the intron 1 of caspase-7 gene at positions $+4088,+7199$, +8918 , and +9091 . We demonstrate that, among these four putative p53-binding sites, the site at +7199 is a functional response element in response to cisplatin or p53 overexpression. However, it is possible that these sites collectively may have better response than the single site. In addition, we have demonstrated p53-dependent transactivation of caspase- 6 and -7 both in vitro in cell cultures and in vivo studies in kidneys from cisplatin-induced AKI.

We have shown that a high level of $p 53$ protein induced by cisplatin exerts its effect in upregulation of mRNA and protein levels of procaspase- 6 and -7. p53-dependent high activities of these caspases suggest enhanced activation of procaspase- 6 and -7 . Thus, p53-dependent increased production of procaspase-6 and -7 may lower apoptotic threshold in cisplatin injury by increased processing of these caspases. The functional significance of p53-dependent caspase-6 and -7 activations in caspase-3 $(-/-)$ cells revealed that these caspases significantly contribute to cell death in cisplatin injury. Inhibition of caspase- 6 by its specific inhibitor VEID-CHO and inhibition of caspase-7 by its inhibitor benzyloxycarbonyl-Asp-Glu-Val-Asp-amino-4-fluoromethylketone (Z-DEVD-fmk) in caspase-3 (-/-) cells provided marked protection from cisplatin injury. In addition, blocking cisplatin-induced p53 induction prevented activation of these caspases and provided marked protection and delayed cisplatin-induced cell death. Recently, caspase-7 was also shown to be crucial to the mitochondrial events of apoptosis including AIF and cytochrome $c$ release ${ }^{26}$ in addition to its role as an executioner caspase. Thus, our studies in part reveal the mechanism whereby cisplatin is able to cause cell death in RTECs. In addition, caspase- $1^{20}$ and $-10^{22}$ genes have been shown previously to be transcriptional target of p53 but at present we do not know their transcriptional activation in response to cisplatin. Our previous study showed that the activity of caspase-1 is not increased in response to cisplatin in kidney cells. ${ }^{12}$ Caspase- 3 is predominately activated in a p53-dependent manner in cisplatin injury in RTECs ${ }^{12,13}$ and in vivo in cisplatin nephrotoxicity but, like initiator caspases, it was not found to be a transcriptional target of p53. In fact, no p53-binding element was found in the caspase-3 gene. Cisplatin-induced caspase- 3 activation can be regulated in a transcriptional-independent manner by multiple pathways mediated by p53. For example, p53 is known to transactivate genes that encode proapoptotic proteins of the $\mathrm{Bcl}-2$ family including Puma, ${ }^{27,28} \mathrm{Noxa}^{29} \mathrm{Bak}^{30}{ }^{30} \mathrm{Bax},{ }^{31} \mathrm{Bid},{ }^{32}$ and p53AIP1, ${ }^{33}$ and recruitment of these proapoptotic molecules on the mitochondrial surface can antagonize the antiapoptotic
Bcl-2 members to trigger the release of cytochrome $c$ and subsequent caspase-3 activation. Also, in a receptor-mediated pathway a number of p53 target genes including DR4, DR5, and $\mathrm{Fas}^{34}$ can result in caspase-8 activation, which subsequently can activate caspase-3. In addition, p53 has an extranuclear role to regulate transcription-independent caspase-3 activation and cell death. The extranuclear p53 can directly activate $\mathrm{Bax}^{35}$ or directly binds to $\mathrm{Bcl}-\mathrm{xL}$ and $\mathrm{Bcl}-2$ proteins to induce mitochondrial permeabilization and release cytochrome $c{ }^{36,37}$ which can promote caspase-3 activation. In addition to the direct transcriptional effect on caspases, their activators, and proapoptotic molecules of the Bcl-2 family, p53 can induce transcriptional repression of antiapoptotic genes ${ }^{38}$ including Bcl-2 and surviving. Thus, direct upregulation of caspases and other proapoptotic molecules by p53 underscores the importance of p53 in cisplatin-induced AKI.

A potent and highly specific pharmacological inhibitor of p53 blocked cisplatin-induced caspase activation and ameliorated renal dysfunction in an experimental model of cisplatininduced AKI. Administration of pifithrin- $\alpha$ did not block induction of caspase- 6 and -7 activation until $4 \mathrm{~h}$ to 1 day in an in vivo experiment. Subsequently, pifithrin- $\alpha$ effectively blocked caspase- 6 and -7 activation at later periods. Unlike the direct exposure of the drug to cells in vitro, to some extent lack of sufficient accessibility of pifithrin- $\alpha$ to the target tissues in the in vivo experiments may also contribute in showing little or no effect of pifithrin- $\alpha$ within a short time period. In addition, we demonstrate that p53 (-/-) mice were resistant to cisplatin-induced AKI. A previous study using a rat model of ischemia-reperfusion injury has shown that p53 protein is an important mediator of renal cell apoptosis whereby inhibition of p53 reduced ischemic injury in rats. ${ }^{39}$

In summary, we have identified caspase- 6 and -7 but not -3 , -8 , and -9 as transcriptional targets of p53 in renal tubular cells and the kidney cortex in response to cisplatin-induced AKI. We have characterized the p53-binding sites in the caspase- 6 and -7 genes. A p53-dependent increased production of procaspase- 6 and -7 resulted in enhanced processing and activation of these caspases in cisplatin injury. Inhibition of p53 either by p53 inhibitor or using p53 (-/-) cells blocked activation of executioner caspases and provided marked protection from cisplatin-induced cell death in vitro in cell culture and preserved renal function and kidney histology in vivo in cisplatin-induced AKI. p53 (-/-) mice ameliorated cisplatin-induced renal dysfunction. These studies identify an important pathway by which cisplatin-induced p53 expression transcriptionally controls caspase- 6 and -7 expression and $\mathrm{AKI}$ in cisplatin nephrotoxicity.

\section{Materials and Methods}

Cell lines and reagents. RTECs used in the study were mouse kidney proximal tubule epithelial cells (TKPTS) and porcine kidney proximal tubule epithelial cells (LLC-PK1) and were cultured as described. ${ }^{12}$ The human cell lines HEK-293, MCF-7, LNCaP, and PA-1 were from ATCC and were cultured under conditions recommended by their depositors. The status of endogenous $p 53$ gene in these cells is wild type. Antibodies to p53 (clone 1C12), Ser-15-phosphorylated p53 (clone 16G8), caspase-3 (clone 3G2), caspase-6 (catalog no. 9762), cleaved caspase-6 (catalog no. 9761), caspase-7 (catalog no. 9492), and cleaved caspase7 (catalog no. 9491 were obtained from Cell Signaling (Beverly, MA, USA). Actin (catalog no. sc-8432) and $\alpha$-tubulin (catalog no. sc-8035) were from Santa Cruz Biotechnology (Santa Cruz, CA, USA). Caspase substrates (4-aminomethyl 
coumarin-tagged), pancaspase inhibitor (benzyloxycarbonyl-Val-Ala-Aspfluoromethylketone), caspase-3 inhibitor (Z-DEVD-fmk), and caspase-6 inhibitor (VEID-CHO) were obtained from Enzyme System Products (Livermore, CA, USA). Cell transfection reagents, primers and one-step RT-PCR kit were from Invitrogen (Carlsbad, CA, USA). SYBR Green PCR master mix for real-time PCR was from Applied Biosystems and RNeasy RNA purification kit was from Qiagen (Chatsworth, CA, USA).

Induction of cisplatin-induced acute renal failure. Animal protocol was approved by the Institutional Animal Care and Use Committee. Mice (SV 129, 8 weeks old, $n=6)$ were given a single intraperitoneal injection of cisplatin $(20 \mathrm{mg} /$ $\mathrm{kg}$ b.w.) or cisplatin $(20 \mathrm{mg} / \mathrm{kg}$ b.w.) plus pifithrin- $\alpha(2 \mathrm{mg} / \mathrm{kg} \mathrm{b} . w$.). Control animals were administered $5 \%$ DMSO in saline. Animals were killed at $4 \mathrm{~h}, 16 \mathrm{~h}, 1$ day, 2 days, and 3 days. Kidneys were used for histology, RNA isolation (kidneys were placed in RNAlater reagent (Qiagen) and stored in liquid nitrogen), and caspase assays. Blood was collected for BUN and serum creatinine level determinations.

Preparation of primary cultures of p53 $(+I+)$, p53(-I-), caspase-3 $(-I-)$, and caspase $(+I+)$ RTECs. Primary cultures of RTECs were prepared from kidneys of the knockout and wild-type mice. Caspase-3 null mice were generously provided by Richard Flavell, PhD. p53 null mice were obtained from Jackson Laboratories. All procedures for the preparation of primary cultures were performed under sterile conditions as described and used in our previous studies. ${ }^{18}$

Immunohistochemistry for p53. Kidney tissue was fixed in phosphatebuffered $4 \%$ formalin $(\mathrm{pH} 7.4)$ for $24 \mathrm{~h}$ and then embedded in paraffin. Sections $(5 \mu \mathrm{m})$ were cut, deparaffinized, incubated with the primary antibody, washed in PBS and incubated with secondary antibody conjugated with horseradish peroxidase.

Immunofluorescence staining for active caspase-3, -6, and -7. Cells were grown on sterile glass coverslips and treated with cisplatin for $16 \mathrm{~h}$. The cells were washed in PBS and fixed in $2 \%$ paraformaldehyde in PBS for $15 \mathrm{~min}$. After washing twice in PBS the cells were permeabilized for $1 \mathrm{~h}$ in blocking buffer containing $1 \% \mathrm{BSA}, 1 \%$ goat serum, $0.1 \%$ saponin, $1 \mathrm{mM} \mathrm{CaCl}, 1 \mathrm{mM}$ $\mathrm{MgCl}_{2}$, and $2 \mathrm{mM} \mathrm{NaV}_{2} \mathrm{O}_{5}$ in PBS. The cells were then incubated with rabbit anti-caspase-3 (active) antibody $(1: 200)$ and goat anti-caspase- 6 (active) or goat anti-caspase-7 (active) antibody for $1 \mathrm{~h}$ in a $37^{\circ} \mathrm{C}$ humidified incubator. After three washes in washing buffer containing $1 \%$ BSA and $0.1 \%$ saponin in PBS the cells were incubated at $37^{\circ} \mathrm{C}$ in a humidified incubator for $1 \mathrm{~h}$ with $1: 500$ of Alexa fluorconjugated secondary antibody (anti-mouse Alexa fluor 488 for caspase- 6 or -7 and anti-rabbit Alexa fluor 594 for caspase-3) in blocking solution and again washed with washing buffer. The nuclei were stained with $0.5 \mu \mathrm{g} / \mathrm{ml} \mathrm{of} 4^{\prime}, 6^{\prime}$-diamidino2-phenylindole for $5 \mathrm{~min}$ and the cells were washed twice in washing buffer. Coverslips were then mounted on slides using antifade mounting media (Molecular Probes). Localization of active caspase- $3,-6$, and -7 and morphological changes of the nuclei were analyzed using a Zeiss Deconvolution microscope.

Caspase activity assay. Cells were harvested, washed twice in cold PBS, lysed, and assayed for caspase activities as described. ${ }^{12}$

Adenoviral infection of cells. Recombinant adenoviral vectors carrying p53, GFP, or lacZ, were generous gifts from Dr. Ruth Slack. The adenoviral infectivity titers for TKPTS cells were determined as described. ${ }^{40}$ TKPTS cells were infected with adenoviral vectors at a multiplicity of infection of 50 plaque-forming units/cell. The efficiency of the infection was confirmed by co-transfection of Ad-GFP or Ad-LacZ followed by staining with 5-bromo-4-chloro-3-indolyl- $\beta$-Dgalactopyranoside (X-gal) for $\beta$-galactosidase expression. The cells were infected with adenovirus p53 or transfected with p53 siRNA $36 \mathrm{~h}$ prior to the treatment of cisplatin.

Electrophoretic mobility shift assay. Oligonucleotides complimentary to the consensus p53 DNA-binding site for the human p21, mouse caspase-6, mouse caspase-7, human caspase-7 (located in intron 1, Figure 3a), and human Pidd genes, and the mutated oligonucleotides for these sites (replacing conserved $C$ and $G$ to $A$ and $T$, respectively, in each consensus half site) were synthesized (Invitrogen). The sequences of the wild-type and mutant oligonucleotides used are as follows: mouse caspase-7 (WT), 5'-AATTCTCGAGAGACTTGTCCCAC
ACGTGGACACACACACAATCACAAGGCTCTCGAGAATT; mouse caspase-7 (Mutant), 5'-AATTCTCGAGAGAACCTTCCCAC ACGTGGACACACACACAATC AACCTGCTCTCGAGAATT, mouse caspase-6 (WT), 5'-AAT TCTCGAGAGCCTT GCAATGCAGGCCTTGCCCCTCGAGAATT; mouse caspase-6 (Mutant), 5'-AATT CTCGAGAGCACCTCAATGCAGGCACCTCCCCTCGAGAATT. Oligonucleotides were labeled with biotin at the $5^{\prime}$-end using the labeling kit (Pierce). The complementary oligonucleotides were annealed and ends were filled using the Klenow fragment of DNA polymerase to produce double-stranded oligonucleotides. Nuclear extracts from RTECs were prepared by high-salt extraction of nuclei using the Sigma CelLytic NUCLEAR extraction kit. Recombinant p53 protein and MCF-7 nuclear extracts were from Active Motif. Binding reactions were performed with LightShift Chemiluminescent Kit according to manufacturer's instructions. For supershift, the cocktail of p53 antibodies (Santa Cruz) were used. The reactions were loaded on 4-20\% TBE ready gel (Invitrogen), transferred to nylon membrane and biotinylated oligos were detected with streptavidin-linked horseradish peroxidase

Luciferase assay. Luciferase reporter plasmids were constructed by cloning either wild-type or mutant p53-binding elements of the mouse caspase-6 $(+3456$ to +3479$)$, mouse caspase- $7(+7198$ to +7238$)$, human caspase $-7(+3953$ to +3972 ), and human p21 ( -2281 to -2256$)$ genes, containing a minimum E1b promoter sequence, into the Kpnl and Hindlll site of pGL2 basic vector (Promega) with the coding region for firefly luciferase. The sequences of the synthetic oligonucleotides containing p53-binding sequences (shown in bold) and a minimum E1b promoter sequence and cloning sites Kpnl and Hindlll (Invitrogen) were the following: mouse caspase-6, 5'-GCGCGGTACCAGCCTTGCAATGCAGGCCTTG CCCGCTAGCGAGCTCAGGGTATATAATGAAGCTTGGCC-3'; human caspase-7 5'-GCGCGGTACCAGGCATGCACCACCATGCCCGCTAGCGCTAGCGAGCTCA GGGTATATAATGAAGCTTGGCCC; mouse caspase-7, 5'-GCGCGGTACCAGAC TTGTCCCACACGTGGACACACACACAATCACAAGGCTGCTAGCGAGCTCAG GGTATATAATGAAGCTTGGCC-3'; p21, GCGCGGTACCGAACATGTCCCAACA TGTTGGCTAGCGAGCTCAGGGTATATAATGAAGCTTGGCC- $3^{\prime}$. The mutated oligonucleotides were synthesized after replacing conserved $C$ and $G$ to $A$ and $T$, respectively.

TKPTS cells were infected with Ad-LacZ, Ad-p53, or Ad-GFP at a multiplicity of infection of 50 . After $24 \mathrm{~h}$, cells were transfected with $8 \mu \mathrm{g}$ reporter plasmid DNA using lipofectamine in Opti-MEM media and assayed for luciferase activity (Promega Luciferase Kit).

Chromatin immunoprecipitation. ChIP assays were performed using ChIP-IT express kit (Active Motif, CA, USA) essentially according to the manufacturer's instructions. Briefly, cells were fixed with formaldehyde, lysed with lysis buffer and the suspension was centrifuged at 5000 r.p.m. to obtain the nuclear pellet. Nuclei were suspended in shearing buffer and sonicated on ice for five pulses, each $20 \mathrm{~s}$, using VirSonic 475 . After centrifugation at 15000 r.p.m., $100 \mu \mathrm{l}$ of the chromatin solution was incubated with p53 antibodies (p53 DO-1 and FL-393) and $25 \mu \mathrm{l}$ Protein G Magnetic Beads in ChIP buffer 1 at $4^{\circ} \mathrm{C}$ for $16 \mathrm{~h}$. For control, actin antibody was used. The immunoprecipitates were washed one time with $800 \mu \mathrm{l} \mathrm{ChIP} \mathrm{buffer} 1$ and two times with ChIP buffer 2. Beads were resuspended with $100 \mu \mathrm{l}$ of elution buffer and incubated at $65^{\circ} \mathrm{C}$ for $2.5 \mathrm{~h}$, and treated with $2 \mu \mathrm{l}$ protease $\mathrm{K}$ at $37^{\circ} \mathrm{C}$ for $1 \mathrm{~h}$. DNA recovered from the immunocomplex and input material were used for PCR using the following primers for p53-binding sites in the caspase-7 gene: intron 1, site 1 ( + 4088), forward $5^{\prime}$-TTCCCTCTCTCCCTCTTT CTG, reverse 5'-GCAAGGCGTGCCTTTAAATA; site $2(+7199)$, forward 5' -GCG AGAGAGCCTGGCTAATA, reverse $5^{\prime}$-AGAGATGCAGAGTGGCGTCT; site $3(+8918)$, forward $5^{\prime}$-ACTTTTTCAGGGGCCTGTGT, reverse $5^{\prime}$-TCTCACCAGTCAGCTTG CTC; site 4 ( + 9091), forward 5'-CCTCATTGAAGAAGGTGGACA, reverse $5^{\prime}$-GA CGTGCCTGTGTATGTTGG; caspase-7 promoter, forward $5^{\prime}$-ACTGGAATC CGTGTGTGTGTG, reverse $5^{\prime}$-ATGCGGCCGGGAGTCAGTCAAAC; Pidd gene, forward 5'-GGTCCCCTACAGCCTACTCC, reverse 5'-ATCACCCATGGAAGGTC CTC. After amplification PCR products were run on $3 \%$ agarose gel and were analyzed by ethidium bromide staining.

Semiquantitative reverse transcription PCR. Total RNA from TKPTS cells or kidney cortex following treatments was prepared using an RNeasy Mini Kit (Qiagen). Approximately $1 \mu \mathrm{g}$ of total RNA was used for reverse transcription and gene-specific amplification using the primer pairs shown in Table 1a. Primers for $\beta$-actin were used as an internal control. 
Quantitation of mRNA expression of caspases by real-time RT-PCR. All primers for real-time RT-PCR were designed using OligoPerfect and D-LUX Designer Software (Invitrogen) following the guidelines based on sequences from GenBank (Table 1b). After optimal primer concentrations were determined, $10 \mathrm{ng}$ of CDNA samples were used for the PCR using SYBR Green chemistry and analyzed using a DNA Engine Opticon 2 Detection System (MJ Research). Cycle threshold $\left(C_{t}\right)$ values were obtained from the Opticon 2 system software and relative levels of various genes were calculated and normalized to that of $\beta$-actin for each sample.

RNA interference. RTECs were plated in a six-well plate with complete medium. When the cells were $60 \%$ confluent, old medium was replaced with fresh medium without serum and antibiotics. Commercially available siRNAs for $\mathrm{p} 53$ (sc29436) and control (sc37007) from Santa Cruz Biotechnology Inc., and for caspase-6 (ID no. 66079) and caspase-7 (ID no. 16007) from Ambion (Austin, TX USA) were used in this study according to the manufacturer's instructions with minor modification as we described previously. ${ }^{18}$

Cell viability and cell apoptosis. Inhibition of cell proliferation was determined by the MTT (Roche Molecular Biochemicals, Laval, PQ) according to the manufacturer's protocol. For the detection of apoptosis, cells were grown on glass coverslips in six-well plates. The cells were treated with caspase inhibitors or pifithrin- $\alpha$ for $1 \mathrm{~h}$ prior to treatment with $50 \mu \mathrm{M}$ cisplatin for $12 \mathrm{~h}$. Apoptosis was

Table 1a Semiquantitative RT-PCR primers

\begin{tabular}{|c|c|c|}
\hline $\begin{array}{l}\text { Genes of } \\
\text { interest }\end{array}$ & $\begin{array}{l}\text { Primer } \\
\text { position }\end{array}$ & Primer sequence \\
\hline Caspase-3 & $\begin{array}{c}\text { Sense (457) } \\
\text { Antisense } \\
(698)\end{array}$ & $\begin{array}{l}\text { 5'-GGGCCTGTTGAACTGAAAAA } \\
\text { 5'-CCGTCCTTTGAATTTCTCCA }\end{array}$ \\
\hline Caspase-6 & $\begin{array}{l}\text { Sense (412) } \\
\text { Antisense } \\
(562)\end{array}$ & $\begin{array}{l}\text { 5'-TTCAGACGTTGACTGGCTTG } \\
\text { 5'-TCCAGCTTGTCTGTCTGGTG }\end{array}$ \\
\hline Caspase-7 & $\begin{array}{c}\text { Sense (850) } \\
\text { Antisense } \\
\text { (1055) }\end{array}$ & $\begin{array}{l}\text { 5'-TTTGCTTACTCCACGGTTCC } \\
\text { 5'-GAGCATGGACACCATACACG }\end{array}$ \\
\hline Caspase-8 & $\begin{array}{c}\text { Sense (1269) } \\
\text { Antisense } \\
(1502)\end{array}$ & $\begin{array}{l}\text { 5'-GGCCTCCATCTATGACCTGA } \\
\text { 5'-TTCTTCACCGTAGCCATTCC }\end{array}$ \\
\hline Caspase-9 & $\begin{array}{c}\text { Sense (1300) } \\
\text { Antisense } \\
(1504)\end{array}$ & $\begin{array}{l}\text { 5'-GATGCTGTCCCCTATCAGGA } \\
\text { 5'-GGGACTGCAGGTCTTCAGAG }\end{array}$ \\
\hline$\beta$-Actin & $\begin{array}{c}\text { Sense (471) } \\
\text { Antisense } \\
(697)\end{array}$ & $\begin{array}{l}\text { 5'-AGCCATGTACGTAGCCATCC } \\
\text { 5'-TCTCAGCTGTGGTGGTGAAG }\end{array}$ \\
\hline
\end{tabular}

Table 1b Quantitative real-time RT-PCR primers

\begin{tabular}{|c|c|c|}
\hline $\begin{array}{l}\text { Genes of } \\
\text { interest }\end{array}$ & $\begin{array}{l}\text { Primer } \\
\text { position }\end{array}$ & Primer sequences \\
\hline Caspase-3 & $\begin{array}{c}\text { Sense (128) } \\
\text { Antisense } \\
(264)\end{array}$ & $\begin{array}{l}\text { 5'-ATGGGAGCAAGTCAGTGGAC } \\
5^{\prime} \text {-CGTACCAGAGCGAGATGACA }\end{array}$ \\
\hline Caspase- 6 & $\begin{array}{c}\text { Sense (545) } \\
\text { Antisense } \\
(687)\end{array}$ & $\begin{array}{l}\text { 5'-CCAGACAGACAAGCTGGACA } \\
\text { 5'-TGTACCAGGAGCCATTCACA }\end{array}$ \\
\hline Caspase-7 & $\begin{array}{c}\text { Sense (348) } \\
\text { Antisense } \\
\text { (438) }\end{array}$ & $\begin{array}{l}\text { 5'-CCGAGTGCCCACTTATCTGT } \\
\text { 5'-ACCTGTCGCTTTGTCGAAGT }\end{array}$ \\
\hline Caspase-8 & $\begin{array}{c}\text { Sense (567) } \\
\text { Antisense } \\
(691)\end{array}$ & $\begin{array}{l}\text { 5'-TTCTCCCTACAGGGTCATGC } \\
\text { 5'-GCAGGCTCAAGTCATCTTCC }\end{array}$ \\
\hline Caspase-9 & $\begin{array}{c}\text { Sense (1399) } \\
\text { Antisense } \\
(1504)\end{array}$ & $\begin{array}{l}\text { 5'-TTCCCAGGTTTTGTCTCCTG } \\
\text { 5'-GGGACTGCAGGTCTTCAGAG }\end{array}$ \\
\hline$\beta$-Actin & $\begin{array}{l}\text { Sense (787) } \\
\text { Antisense } \\
(988)\end{array}$ & $\begin{array}{l}\text { 5'-CTGGAGAAGAGCTATGAGCTGCCG } \\
5^{\prime} \text {-TGCCACCAGACAGCACTGTGTT }\end{array}$ \\
\hline
\end{tabular}

detected following the TUNEL assay using a TdT-FragEL DNA fragmentation detection kit (catalog no. QIA33, Calbiochem, La Jolla, CA, USA) according to the manufacturer's instructions. Images were viewed and captured using an Olympus microscope with digital camera model DP71 and the apoptotic cells were counted in five fields and compared by two-tailed unpaired $t$-tests between the two groups.

Acknowledgements. This work was supported by the NIDDK funded program project, project 2 (PI, GPK) (Program Director, SVS) and VA merit to GPK. We thank Ms. Cindy Reid for technical editing assistance.

1. Arany I, Safirstein RL. Cisplatin nephrotoxicity. Semin Nephrol 2003; 23: 460-464.

2. Bonegio R, Lieberthal W. Role of apoptosis in the pathogenesis of acute renal failure. Curr Opin Nephrol Hypertens 2002; 11: 301-308.

3. Jamieson ER, Lippard SJ. Structure recognition and processing of cisplatin-DNA adducts. Chem Rev 1999; 99: 2467-2498.

4. Wang D, Lippard SJ. Cellular processing of platinum anticancer drugs. Nat Rev Drug Discov 2005; 4: 307-320.

5. El-Deiry WS. The role of p53 in chemosensitivity and radiosensitivity. Oncogene 2003; 22 : 7486-7495.

6. Vogelstein B, Lane D, Levine AJ. Surfing the p53 network. Nature 2000; 408: 307-310.

7. Harris SL, Levine AJ. The p53 pathway: positive and negative feedback loops. Oncogene 2005; 24: 2899-2908.

8. Vousden KH, Lu X. Live or let die: the cell's response to p53. Nat Rev Cancer 2002; 2: 594-604.

9. Wei CL, Wu Q, Vega VB, Chiu KP, Ng P, Zhang T et al. A global map of p53 transcriptionfactor binding sites in the human genome. Cell 2006; 124: 207-219.

10. Bouvard V, Zaitchouk T, Vacher M, Duthu A, Canivet M, Choisy-Rossi C et al. Tissue and cell-specific expression of the p53-target genes: bax fas mdm2 and waf1/p21 before and following ionising irradiation in mice. Oncogene 2000; 19: 649-660.

11. Fei $\mathrm{P}$, Bernhard EJ, El-Deiry WS. Tissue-specific induction of $\mathrm{p} 53$ targets in vivo. Cancer Res 2002; 62: 7316-7327.

12. Kaushal GP, Kaushal V, Hong X, Shah SV. Role and regulation of activation of caspases in cisplatin-induced injury to renal tubular epithelial cells. Kidney Int 2001; 60: 1726-1736.

13. Tsuruya K, Ninomiya T, Tokumoto M, Hirakawa M, Masutani K, Taniguchi M et al. Direct involvement of the receptor-mediated apoptotic pathways in cisplatin-induced renal tubular cell death. Kidney Int 2003; 63: 72-82.

14. Sheikh-Hamad D, Cacini W, Buckley AR, Isaac J, Truong LD, Tsao CC et al. Cellular and molecular studies on cisplatin-induced apoptotic cell death in rat kidney. Arch Toxicol 2004; 78: $147-155$

15. Faubel S, Ljubanovic D, Reznikov L, Somerset H, Dinarello CA, Edelstein CL. Caspase1-deficient mice are protected against cisplatin-induced apoptosis and acute tubular necrosis. Kidney Int 2004; 66: 2202-2213.

16. Cummings BS, Schnellmann RG. Cisplatin-induced renal cell apoptosis: caspase 3-dependent and -independent pathways. J Pharmacol Exp Ther 2002; 302: 8-17.

17. Jiang M, Yi X, Hsu S, Wang CY, Dong Z. Role of p53 in cisplatin-induced tubular cell apoptosis: dependence on p53 transcriptional activity. Am J Physiol Renal Physiol 2004; 287: F1140-F1147.

18. Seth R, Yang C, Kaushal V, Shah SV, Kaushal GP. p53-dependent caspase-2 activation in mitochondrial release of apoptosis-inducing factor and its role in renal tubular epithelial cell injury. J Biol Chem 2005; 280: 31230-31239.

19. Megyesi J, Udvarhelyi N, Safirstein RL, Price PM. The p53-independent activation of transcription of p21 WAF1/CIP1/SDI1 after acute renal failure. Am J Physiol 1996; 271: F1211-F1216.

20. Gupta S, Radha V, Furukawa $Y$, Swarup G. Direct transcriptional activation of human caspase-1 by tumor suppressor p53. J Biol Chem 2001; 276: 10585-10588.

21. MacLachlan TK, El-Deiry WS. Apoptotic threshold is lowered by $\mathrm{p} 53$ transactivation of caspase-6. Proc Natl Acad Sci USA 2002; 99: 9492-9497.

22. Rikhof $B$, Corn PG, El-Deiry WS. Caspase 10 levels are increased following DNA damage in a p53-dependent manner. Cancer Biol Ther 2003; 2: 707-712.

23. El-Deiry WS, Kern SE, Pietenpol JA, Kinzler KW, Vogelstein B. Definition of a consensus binding site for p53. Nat Genet 1992; 1: 45-49.

24. Chipuk JE, Green DR. Dissecting p53-dependent apoptosis. Cell Death Differ 2006; 13 : 994-1002.

25. Joshi B, Rastogi S, Morris M, Carastro LM, DeCook C, Seto E et al. Differential regulation of human $\mathrm{YY} 1$ and caspase 7 promoters by prohibitin through E2F1 and p53 binding sites. Biochem J 2007; 401: 155-166.

26. Lakhani SA, Masud A, Kuida K, Porter Jr GA, Booth CJ, Mehal WZ et al. Caspases 3 and 7: key mediators of mitochondrial events of apoptosis. Science 2006; 311: 847-851.

27. Nakano K, Vousden KH. PUMA a novel proapoptotic gene is induced by p53. Mol Cell 2001; 7: 683-694.

28. Yu J, Wang Z, Kinzler KW, Vogelstein B, Zhang L. PUMA mediates the apoptotic response to p53 in colorectal cancer cells. Proc Natl Acad Sci USA 2003; 100: 1931-1936. 
29. Oda E, Ohki R, Murasawa H, Nemoto J, Shibue T, Yamashita T et al. Noxa a BH3-only member of the Bcl-2 family and candidate mediator of p53-induced apoptosis. Science 2000; 288: 1053-1058.

30. Pearson AS, Spitz FR, Swisher SG, Kataoka M, Sarkiss MG, Meyn RE et al. Up-regulation of the proapoptotic mediators Bax and Bak after adenovirus-mediated $\mathrm{p} 53$ gene transfer in lung cancer cells. Clin Cancer Res 2000; 6: 887-890.

31. Miyashita T, Reed JC. Tumor suppressor p53 is a direct transcriptional activator of the human bax gene. Cell 1995; 80: 293-299.

32. Sax JK, Fei P, Murphy ME, Bernhard E, Korsmeyer SJ, El-Deiry WS. BID regulation by p53 contributes to chemosensitivity. Nat Cell Biol 2002; 4: 842-849.

33. Oda K, Arakawa H, Tanaka T, Matsuda K, Tanikawa C, Mori T et al. p53AIP1 a potential mediator of p53-dependent apoptosis and its regulation by Ser-46-phosphorylated p53. Cell 2000; 102: 849-862.

34. Wajant H. CD95L/FasL and TRAIL in tumour surveillance and cancer therapy. Cancer Treat Res 2006; 130: 141-165.
35. Chipuk JE, Kuwana T, Bouchier-Hayes L, Droin NM, Newmeyer DD, Schuler M et al. Direct activation of Bax by p53 mediates mitochondrial membrane permeabilization and apoptosis. Science 2004; 303: 1010-1014.

36. Mihara M, Erster S, Zaika A, Petrenko O, Chittenden T, Pancoska $\mathrm{P}$ et al. p53 has a direct apoptogenic role at the mitochondria. Mol Cell 2003; 11: 577-590.

37. Moll UM, Wolff S, Speidel D, Deppert W. Transcription-independent pro-apoptotic functions of p53. Curr Opin Cell Biol 2005; 17: 631-636.

38. Ho J, Benchimol S. Transcriptional repression mediated by the p53 tumour suppressor Cell Death Differ 2003; 10: 404-408.

39. Kelly KJ, Plotkin Z, Vulgamott SL, Dagher PC. P53 mediates the apoptotic response to GTP depletion after renal ischemia-reperfusion: protective role of a p53 inhibitor. J Am Soc Nephrol 2003; 14: 128-138.

40. Cregan SP, MacLaurin J, Gendron TF, Callaghan SM, Park DS, Parks RJ et al. Helperdependent adenovirus vectors: their use as a gene delivery system to neurons. Gene Therapy 2000; 7: 1200-1209. 